\title{
Gender-Based Taxation and the Division of Family Chores
}

\section{Citation}

Alesina, Alberto, Andrea Ichino, and Loukas Karabarbounis. 2011. Gender-Based Taxation and the Division of Family Chores. American Economic Journal: Economic Policy 3, no. 2: 1-40. doi:10.1257/pol.3.2.1.

\section{Published Version}

doi:10.1257/pol.3.2.1

\section{Permanent link}

http://nrs.harvard.edu/urn-3:HUL.InstRepos:30752834

\section{Terms of Use}

This article was downloaded from Harvard University's DASH repository, and is made available under the terms and conditions applicable to Open Access Policy Articles, as set forth at http:// nrs.harvard.edu/urn-3:HUL.InstRepos:dash.current.terms-of-use\#OAP

\section{Share Your Story}

The Harvard community has made this article openly available.

Please share how this access benefits you. Submit a story.

Accessibility 


\title{
Gender-Based Taxation and the Division of Family Chores *
}

\author{
Alberto Alesina \\ HARVARD UNIVERSITY \& IGIER \\ Andrea Ichino \\ Loukas Karabarbounis \\ University of Chicago
}

September 2010

\begin{abstract}
Gender-Based Taxation (GBT) satisfies Ramsey's rule of optimality because it taxes at a lower rate the more elastic labor supply of women. This holds when different elasticities between men and women are taken as exogenous. We study GBT in a model in which labor supply elasticities emerge endogenously from the bargained allocation of goods and time in the family. We explore the cases of superior bargaining power for men, higher men wages and higher women productivity in home duties. In all cases, men commit to a career in the market and take less home duties than women. As a result, their market work becomes less substitutable to home duty and their labor supply responds less to changes in the market wage. When society can resolve its distributional concerns efficiently with gender-specific lump sum transfers, GBT with higher marginal tax rates on (single and married) men is optimal. In addition, GBT affects the intrafamily bargaining, leading to a more balanced allocation of labor market outcomes across spouses and a smaller gender gap in labor supply elasticities.
\end{abstract}

JEL-Code: D13, H21, J16, J20.

Keywords: Optimal Taxation, Economics of Gender, Family Economics, Elasticity of Labor Supply.

${ }^{*}$ We thank George Akerlof, George-Marios Angeletos, Steven Davis, Claudia Goldin, Larry Katz, Steve Pischke, James Poterba, Emmanuel Saez, Ivan Werning, Stephen Zeldes, seminar participants in many universities and our discussant, Stefania Albanesi, at the 2009 ASSA Meetings for helpful suggestions. The Editor (Alan Auerbach) and two anonymous referees provided very useful comments. Karabarbounis acknowledges financial support from the Neubauer Family Faculty Fund at Chicago Booth. 


\section{Introduction}

According to optimal taxation theory a benevolent government should tax less individuals who have a more elastic labor supply. The labor supply of women is more elastic than the labor supply of men. Therefore, tax rates on labor income should be lower for women than for men.

This argument is known in the academic literature, but currently it is hardly taken seriously as a policy proposal. ${ }^{1}$ On the contrary, as Table 1 shows, many OECD countries effectively impose higher marginal tax rates on married women's decision to participate in the labor market, relative to the tax rate on singles. ${ }^{2}$ It is surprising that while the simple proposal of taxing women less than men has never been seriously "on the table," a host of other gender-based policies are routinely discussed, and often implemented, such as genderbased affirmative action, quotas, different retirement policies for men and women, child care subsidies and maternal leaves. ${ }^{3}$ This is puzzling because a system of differentiated taxes by gender is also likely to achieve the goals of these interventions (namely, to promote female employment) but possibly with fewer distortions.

The optimality of Gender-Based Taxation (GBT) hinges on the assumption that men and women have different elasticities of labor supply. If the labor supply elasticity is taken as a primitive, exogenous parameter that differentiates genders, then the argument is straightforward. GBT generates gains in welfare, income and employment because it minimizes the aggregate social loss from distortionary labor income taxation. However, differences in the labor supply functions of men and women, including their elasticities, most likely do not only depend on innate characteristics or preferences but may emerge endogenously from the

\footnotetext{
${ }^{1}$ As part of the Reagan tax cut of 1981 , a $10 \%$ of earnings deduction for secondary earners effectively reduced women's marginal tax rates. However, the deduction was abolished five years later by the Tax Reform Act of 1986. See Bosworth and Burtless (1992) for the effects of these tax reforms on labor supply. Two proposals of tax reform explicitly aimed at introducing forms of gender-based taxation have been presented to the Italian Parliament in 2010, but they have not yet been taken into consideration by the parliamentary agenda.

${ }^{2}$ Joint taxation typically results in higher marginal tax rates for women as the income of the second earner is pooled with that of the first earner. Even with separate taxation, the participation decision of second earners is effectively taxed at a higher rate, relative to that of singles, in systems where the dependent spouse allowance is lost when both family members work or due to other similar family-based measures. In addition, in countries where retired couples receive pensions that increase with the benefit of the highest earner, the effective payroll tax of first earners is lower than that of second earners (Feldstein and Liebman, 2002). For instance, in the US a retired couple receives $150 \%$ of the pension of the highest earner, which implies that married men close to retirement face a close to zero (or even negative) social security marginal tax rate.

${ }^{3}$ For instance, gender-based affirmative action is common in the US. Spain and Norway have recently introduced stringent quota systems in favor of women. Public support for child care is common in many European countries. Sweden has recently reformed its paternal leave policy with the goal of inducing men to stay more at home with children and women to participate more continuously in the labor market.
} 
internal organization of the family. In fact, as documented by Goldin (2006), Blau and Kahn (2007) and Albanesi and Olivetti (2007), both the participation rate and the elasticity of labor supply of women evolve over time as a result of technologically or culturally induced change in the family. ${ }^{4}$ Despite the importance of the elasticity of labor supply for income taxation theory, its deeper causes have been little explored in the literature. ${ }^{5}$

Therefore, we explore the implications of GBT in a model in which the elasticities of labor supply arise endogenously from the internal organization of the family. We consider a representative married couple in a collective family model with individualistic preferences and Pareto efficient allocations. The economies of scale and the public goods provision that family members enjoy imply an equilibrium in which everybody marries but the allocation of utilities in the marriage is determined by the off-equilibrium utility when single. Spouses Nash-bargain on the allocation of market goods, household goods, working time in the market and home duties. Any distributional consideration in the family is resolved efficiently by appropriate side payments. The elasticity of labor supply increases in the ratio of home duties to market work, indicating that as the market wage changes, market hours respond more for the spouse who can find more substitutes to his or her market work. The positive association between the amount of home duties and the elasticity of labor supply in our model accords well with recent evidence. ${ }^{6}$ Finally, we also consider the effects of a pre-marital career choice. Committing to a high-wage career is costly in terms of effort and stress but allows workers to do well in the market by acquiring specific technical skills that offer higher returns in the market.

We consider two broad cases that sustain a gendered equilibrium. One is the case in which women assume more home duties because they have a comparative advantage in them. This case can arise when men receive exogenously (i.e. for a given career decision) a higher wage than women in the market or when women are, for exogenous reasons, more productive (or derive more pleasure) than men in performing home duties. This case leads to a gendered equilibrium with unbalanced allocations of market and home work both because of differences in preference or technology parameters and because men, in anticipation of their exogenous comparative advantage, decide to commit to a high-wage career in the market.

While it is certainly a fact that women take more home duties than men, as pointed out

\footnotetext{
${ }^{4}$ Alesina and Giuliano (2010) study the effects of different cultural traits and family values on women's labor force participation. Ichino and Moretti (2009) show instead how more persistent biological gender differences may affect the absenteeism of men and women and, indirectly, the labor market equilibrium.

${ }^{5}$ Kaplow (2008, 339-341) discusses the importance of pursuing this research agenda.

${ }^{6}$ Aguiar and Hurst (2007) and Blau and Kahn (2007) document decreases in the (woman to man) ratio of home duties and in the ratio of elasticities of labor supply in the last two decades. These ratios, however, still remain well above one.
} 
by the time use studies of Aguiar and Hurst (2007) and Burda, Hamermesh and Weil (2007), whether this is because women have a comparative advantage in home duties is questionable in modern times, as argued by Albanesi and Olivetti (2007), given the technological advancement in the household sector. Thus, we explore a second case in which, for cultural or historical reasons from a period of time where physical power mattered, men have a higher bargaining power than women. In this case, career choices, effective wages, the allocation of working time and the elasticities of labor supply differ across genders even though men and women are identical in their inherent market and home productivity.

When bargaining power is unbalanced, on the one hand women tend to pursue higherwage careers than men in order to increase their implicit bargaining power and offset the cultural or historical bias. But on the other hand, men anticipate that by committing to a higher-wage career they will be able to appropriate a larger share of the enlarged "marital pie" because of their superior bargaining power. When the economies of scale at the household level become relatively important, men's incentive to choose a career with higher wages than women and to appropriate a larger share of the enlarged marital surplus increases. As a result of differences in pre-marital commitments to careers, men work more in the market, take less home duties and earn more than their spouses. Men's labor supply is less sensitive to changes in the wage since what matters for them, relative to women, is also the utility they derive from committing to a career in the market with longer market hours and less home duties.

Given the success of the model to explain several facts of the time use behavior of men and women, we consider the optimal gender-specific linear tax schedule. Our setup is closer to the Ramsey tradition since we postulate the tax schedule, rather than derive it from informational frictions as in the Mirrlees tradition. Importantly, our gender-specific tax schedules apply to individuals regardless of marital status. This is quite different than analyzing the policy of applying different income taxes only to married because the differential taxation of singles affects the outside option of married and thus the bargaining positions within the marriage.

The family bargaining, even if fully efficient, does not internalize how a given allocation of goods and time affects government finances. Imagine that, for one of the above reasons, in equilibrium the family bargaining produces an allocation of goods and time such that the labor supply and the career elasticities of men and women are different, namely higher for women. Then, the government faces an incentive to tax men and women differently in order to minimize the distortionary costs of taxation according to the Ramsey (1927) "inverse elasticity rule." If the society can resolve any distributional concern efficiently (e.g. by making gender-specific lump sum transfers), then the slope of the tax schedule is solely determined 
by the gender difference in elasticities. In turn, the family reacts to the differentiated tax rates and evolves to an equilibrium with more balanced allocations of career opportunities and home duties across genders. As a result, GBT endogenously closes the gender elasticity gap. We show how this fixed point problem leads, under mild conditions, to an equilibrium with higher marginal tax rates for men and labor supply elasticities that have converged relative to the case of non-differential taxation by gender.

Relative to models in which the labor supply elasticity is taken as an exogenous parameter, we can also interpret our model in terms of a difference between short versus long-run effects of GBT. The case in which labor supply functions and their different elasticities across genders are exogenous can be interpreted as the short-run, namely an horizon in which the family organization is not likely to change. In the long-run, instead, the family responds to government policies and evolves to a new equilibrium with a different organization.

We illustrate the link between our model and the literature in Section 2. Section 3 discusses the model and Section 4 presents its solution. Section 5 analyzes the existence of a gendered equilibrium. Section 6 discusses Gender-Based Taxation. Section 7 presents caveats and several extensions for future research. The Appendix contains details of our derivations.

\section{Related Literature}

The paper lies at the intersection of three research strands. The first is concerned with the structure of the family. ${ }^{7}$ The traditional "unitary" approach, in the spirit of Samuelson (1956) and Becker (1974), treats households as single decision making units. This approach lacks the foundations to conduct intrahousehold welfare analysis. ${ }^{8}$ The "collective approach" to family modeling, initiated by Chiappori $(1988,1992)$ and Apps and Rees (1988), builds on individualistic preferences and postulates that collective decisions lie on the Pareto frontier. Manser and Brown (1980) and McElroy and Horney (1981) were the first to "select" a specific point on the Pareto frontier by assuming that family members Nash-bargain on the allocation of commodities. Our model belongs to the collective approach with Nash-bargained allocations.

The second relevant strand of literature refers to the taxation of couples. Rosen (1977) and mainly Boskin and Sheshinski (1983) were the first to point out the efficiency gains from the differential taxation of men and women. ${ }^{9}$ This argument also relates to the insight that

\footnotetext{
${ }^{7}$ See Lundberg and Pollak (1996) and Vermeulen (2002) for excellent surveys.

${ }^{8}$ Two notable empirical failures of the unitary model are the restrictions that arise from the income pooling hypothesis and the symmetry of the Slutsky matrix. See Thomas (1990), Browning, Bourguignon, Chiappori and Lechene (1994), Lundberg, Pollak and Wales (1997) and Browning and Chiappori (1998).

${ }^{9}$ The argument was raised using variants of the Diamond and Mirrlees (1971a and 1971b) and Atkinson
} 
taxes should be conditioned on non-modifiable characteristics as in Akerlof (1978) and Kremer (2003). ${ }^{10}$ The conventional wisdom regarding lower taxes for women can be challenged or reinforced in at least three ways. First, it might be the case that women's tax rate is a more efficient policy instrument when considering redistribution across households. Apps and Rees (2007) place the conventional wisdom on a firmer basis and give intuitive and empirically plausible conditions under which it is optimal to tax men at a higher rate even with heterogeneous households. Second, Piggott and Whalley (1996) raise the issue of intrahousehold distortion of efficiency in models with household production. Since the optimal tax schedule must maintain productive efficiency (Diamond and Mirrlees 1971a), imposing differential tax treatment distorts the intrahousehold allocation of resources and raises a further cost for the society. Apps and Rees (1999b) and Gottfried and Richter (1999) show that the cost of distorting the intrahousehold allocation of resources cannot offset the gains from taxing on an individual basis according to the standard Ramsey principle. We explore the optimality of GBT in a model in which a third potential critique applies. This is the case in which intrahousehold redistribution is explicitly taken into account and the elasticities of labor supply emerge endogenously from family bargaining. ${ }^{11}$

The third strand of literature explains gender differences in labor markets. In Becker (1985) gender differences in earnings arise when women undertake tiring activities that reduce work effort. So, workers with the same level of human capital, earn wages that are inversely related to their housework commitment. The substitutability between home duties and market earnings also arises in our model, although we also consider the effect of a costly career choice. Traditional theories assume that women have a comparative advantage in home production and men in market production, but Albanesi and Olivetti (2007) show how improved medical capital and the introduction of the infant formula have reduced the importance of this factor. Greenwood, Seshadri and Yorukoglu (2005) focus instead on the

and Stiglitz (1972) frameworks. The elasticity of labor supply is also a key parameter in the Mirrlees (1971) framework. For an ambitious paper that takes the latter approach see Kleven, Kreiner and Saez (2009). In a Mirrleesian framework with non-linear tax schedules, there are two factors that favor GBT. First, all else equal, the optimal tax formula supports a uniformly lower marginal tax rate for women because of the inverse elasticity rule (see e.g. Diamond, 1998). In addition, since the distribution of income for women has more mass concentrated towards the low income levels, its hazard rate is typically higher and therefore marginal tax rates for women should be lower. See also Cremer, Gahvari and Lozachmeur (2010) who develop analytical results for income tagging with two groups that differ in their ability distribution.

${ }^{10}$ Weinzierl (2008) analyzes the benefits of age-based taxation which is related but not equivalent to other tags such as gender or height. Mankiw and Weinzierl (2010) apply the idea of tagging to height and discuss the validity of the welfarist approach to optimal taxation.

${ }^{11}$ Brett (1998) is an important earlier paper discussing intrahousehold redistribution. See also Apps and Rees (1999a, 2007) for models with household production. Gugl (2009) analyzes the effects of income splitting on intrahousehold distribution. 
introduction of labor-saving consumer durables (such as washing machines and vacuum cleaners) which liberated women from chores and expanded their labor market participation. In a model with incentive constraints, Albanesi and Olivetti (2009) argue that gender differences arise from firms' expectations that the economy is on a gendered equilibrium.

Regarding the elasticity of labor supply, Goldin (2006) documents that the fast rise of married women's labor supply elasticity over 1930-1970 resulted from a decreasing income effect and an increasing, due to part time employment, substitution effect. During the last thirty years, she argues, women started viewing employment as a long term career rather than as a job and the substitution effect decreased. This interpretation is consistent with how we model the elasticity effect of a commitment to stay in the labor market in order to take advantage of the opportunities offered by it. Blundell and MaCurdy (1999) find a large gender difference in own wage elasticities for married couples, with men's elasticities near zero and women's at 0.8 in the 1970s and the 1980s. Blau and Khan (2007) document and quantify the reduction in the labor elasticity of married women in the US in the 1980s and 1990s. However, this elasticity remains well above that of men, at a ratio of about 4 to 1. Even in Sweden where gender differences in labor market outcomes are arguably less dramatic than elsewhere, Gelber (2010) estimates that married women's elasticity of labor supply is twice as large as married men's elasticity of labor supply.

\section{The Model}

The timing of the model is the following. First, the government chooses the tax policy. We consider gender-specific linear tax schedules of the form:

$$
T_{i}=\tau_{i} I_{i}-\pi_{i}
$$

where $i=m, f$ denotes the gender, $I_{i}$ is total labor income, $\tau_{i} \geq 0$ is the marginal tax rate, $\pi_{i}$ is a lump sum transfer (when positive) and $T_{i}$ is the total tax liability. The government raises revenues to finance an exogenous level of expenditure, $T_{m}+T_{f} \geq G>0$.

Second, given the tax schedule and before the couple decides whether to marry or not, men and women choose non-cooperatively their career $e_{i}$. We interpret $e_{i}$ as all those commitments that allow workers to choose a market career with high wages, including investing effort in acquiring technical skills. ${ }^{12}$ There is a continuum of careers ordered by their salary per unit of

\footnotetext{
${ }^{12}$ While it is well known that the gender gap in college education has reversed (Goldin, Katz and Kuziemko, 2006), it is still a fact that men specialize in more technical subjects that offer higher returns in the job market. For example, Zafar (2009) documents that in 1999-2000, among recipients of bachelor's degrees in the United
} 
hour worked, $w_{i} e_{i}$. In other words, the choice of career $e_{i}$ produces labor income $I_{i}=w_{i} e_{i} n_{i}$, where $w_{i}$ is the exogenous wage rate and $n_{i}$ is total hours worked in the market. ${ }^{13}$ Thus, choosing a higher-wage career (a higher $e_{i}$ ) acts like a labor demand shifter and increases the effective wage $\left(w_{i} e_{i}\right)$ of supplying $n_{i}$ hours of work in the market. However, pursuing a higher-wage career is costly in terms of time and effort to acquire technical skills and produces more stress in the market. Careers are chosen to maximize expected utility:

$$
\max _{e_{i}} \Omega_{i}=\Phi\left(e_{i}\right)-C\left(e_{i}\right)
$$

where $\Phi\left(e_{i}\right)$ denotes the (net of career costs) expected utility of spouse $i=m, f$ and $C\left(e_{i}\right)$ denotes career costs. The cost function satisfies $C^{\prime}>0$ and $C^{\prime \prime}>0$ and has a constant elasticity of marginal cost, $E=C^{\prime \prime} e / C^{\prime}$.

Third, given the tax schedule and the career choice, the representative couple decides whether to marry or to remain single. If the couple decides to marry, then men and women Nash-bargain on side payments and the allocation of consumption goods, household goods (public and private) and working time in the market and at home. First, we discuss the utility function. Second, we specify the threat points in the bargaining problem which we take to be the utility when single. ${ }^{14}$ Third, we describe the Nash-bargaining problem.

\subsection{Preferences}

We adopt the following utility function:

$$
U=c+\widetilde{H}(.)-\frac{1}{1+\phi}(n+h)^{1+\phi}
$$

where $c$ is consumption of the market good, $\widetilde{H}($.$) is consumption of household goods, n$ is hours of market work, $h$ is the amount of home duties and $\phi>0$ is the curvature of the disutility of working a total of $n+h$ hours. The household good, $\widetilde{H}($.$) , depends on own home duties for$

States, $13 \%$ of women majored in education compared to $4 \%$ of men and only $2 \%$ of women majored in engineering compared to $12 \%$ of men.

${ }^{13}$ The exogeneity of $w_{i}$ means a flat labor demand by gender. With a downward sloping labor demand, GBT has two opposing effects on women's pre-tax wages, $w_{f}$. Holding constant women's career choice $e_{f}$, an upward sloping labor supply and a downward sloping labor demand function, imply a fall in pre-tax wages when $\tau_{f}$ falls. But as we show below, lowering women's taxes leads women to choose higher-wage careers $e_{f}$, which endogenously shifts the labor demand upward. This makes the change in pre-tax wages $w_{f}$ theoretically ambiguous even when labor demand is downward sloping.

${ }^{14}$ As we discussed in Section 2, our model extends the models of Manser and Brown (1980) and McElroy and Horney (1981). Lundberg and Pollak (1993), instead, argue that threat points are internal to the marriage and can be seen as (possibly inefficient) non-cooperative equilibria of the marriage game. While the literature is not conclusive as to the most appropriate assumption, we expect the qualitative implications of our model to go through in this alternative environment. The reason is that tax policy affects outside options similarly in our model (because GBT is applied to singles as well) and in a model of internal threat points. 
singles and on own and spouse's home duties for married in a manner that we specify below. The linearity of utility with respect to market consumption allows us to obtain analytical solutions but also has a number of important implications for our results. ${ }^{15}$ Denoting by $\alpha$ the returns to scale parameter in the household technology, this utility specification leads to a wage elasticity of labor supply (see Section 5 for the derivation):

$$
\epsilon_{n, w}=\frac{\partial n}{\partial w} \frac{w}{n}=\frac{1}{\phi}+\left(\frac{1}{\phi}+\frac{1}{1-\alpha}\right) \frac{h}{n}
$$

When $h=0$, the elasticity of labor supply is constant $(1 / \phi)$. Our utility specification implies that the elasticity of labor supply increases in the ratio of home duties over market work, $h / n$. This is a crucial feature of our model. The intuition is that a higher amount of home duties implies the existence of more (or closer) substitutes towards which time spent in market work is directed following shocks that affect the returns of working in the two sectors. As a result, exogenous changes in market wages have larger substitution effects on the labor supply of the spouse who performs more home duties.

A key result in our model, as we discuss in Section 5 , is that the ratio $h / n$ differs across genders. This happens for two reasons. One is the case in which women have a comparative advantage in home duties. Because women perform more home duties, their home production provides a closer substitute to market work and their elasticity of labor supply is higher. The second is the case in which genders are equally productive in market and home activities but, because of higher bargaining power, men pursue higher-wage careers than women. The commitment to a market career with higher wages, longer market hours and less home duties implies that as the wage changes, men's labor supply responds less than women's labor supply. As an example, consider the case of a man who majors in engineering and a woman who majors in education. Because the wife gets involved more with home duties, her time at home becomes a closer substitute to her time in the market relative to the time of her engineer husband.

\section{$3.2 \quad$ Singles}

In the equilibrium of our model there will be no singles. But we analyze their choices because their utility functions are the threat points in the bargaining game. Singles choose market consumption $\left(c_{i}^{s}\right)$, market hours $\left(n_{i}^{s}\right)$ and the amount of home duties $\left(h_{i}^{s}\right)$ to maximize utility:

$$
\max _{c_{i}^{s}, n_{i}^{s}, h_{i}^{s}} U_{i}^{s}=c_{i}^{s}+H_{i}^{s}-\frac{1}{1+\phi}\left(n_{i}^{s}+h_{i}^{s}\right)^{1+\phi}
$$

\footnotetext{
${ }^{15}$ We discuss below how this assumption affects: (i) the application of the Coase theorem; (ii) the absence of strategic interaction in the choice of careers; (iii) the distributional goals of the government.
} 
subject to the budget constraint:

$$
c_{i}^{s} \leq\left(1-\tau_{i}\right) w_{i} n_{i}^{s} e_{i}+\pi_{i}
$$

and the home production technology:

$$
H_{i}^{s} \leq \frac{\kappa_{i}}{\alpha}\left(h_{i}^{s}\right)^{\alpha}
$$

There are decreasing returns to scale in home production, i.e. $\alpha<1$. The parameter $\kappa_{i}>0$ denotes gender-specific productivity in home duties. While we consider a model of a representative family in which it is optimal to marry, the off-equilibrium utility when single determines the implicit bargaining power which affects the marriage solution. As $U_{i}^{s}$ increases, the threat to remain single becomes stronger and spouse $i$ receives higher utility in the marriage. Because the same tax schedule applies to singles and to married (i.e. $\tau_{i}$ and $\pi_{i}$ are not indexed by $s$ ), GBT affects the bargaining positions in the marriage through $U_{i}^{s}$.

\subsection{Married Couple}

Men and women each marry if their respective utility in the marriage exceeds their utility when single. In our model there are two reasons why a couple benefits from marrying. First, there are economies of scale in the market good. Specifically, for every dollar of income the family can consume goods that are worth $z>1$ dollars. ${ }^{16}$ Second, married couples enjoy the provision of a public household good, $H$, as we describe below.

The family allocates market consumption $\left(c_{m}\right.$ and $\left.c_{f}\right)$, private home goods $\left(H_{m}\right.$ and $\left.H_{f}\right)$, market time $\left(n_{m}\right.$ and $\left.n_{f}\right)$ and home duties $\left(h_{m}\right.$ and $\left.h_{f}\right)$ to maximize the Nash product:

$$
\max _{c_{m}, c_{f}, n_{m}, n_{f}, h_{m}, h_{f}, H_{m}, H_{f}} \Omega=\left(U_{m}-U_{m}^{s}\right)^{\gamma}\left(U_{f}-U_{f}^{s}\right)^{1-\gamma}
$$

where $\gamma$ measures the explicit or culturally inherited bargaining power of men. Career costs, $C\left(e_{i}\right)$, are not included in the marital surplus because they are incurred independently of marital status (i.e. $C\left(e_{i}\right)$ is sunk). Utility for married is:

$$
U_{i}=c_{i}+\left(H_{i}+H\right)-\frac{1}{1+\phi}\left(n_{i}+h_{i}\right)^{1+\phi}
$$

where $H_{i}+H$ denotes total consumption of home goods. The family budget constraint is: ${ }^{17}$

$$
\frac{c_{m}+c_{f}}{z} \leq\left(1-\tau_{m}\right) w_{m} n_{m} e_{m}+\left(1-\tau_{f}\right) w_{f} n_{f} e_{f}+\pi_{m}+\pi_{f}
$$

\footnotetext{
${ }^{16}$ For instance, families reduce costs by sharing a ride to work or by reducing waste in food preparation. See Nelson (1988) for an analysis of household economies of scale. See Browning, Chiappori and Lewbel (2006) for a critique of equivalence scales based on the distinction between the unitary and the collective model.

${ }^{17}$ Implicit in equation $(10)$ is the assumption that spouses can make side payments. Let $l$ denote a side payment from the woman to the man. Consider the individual budget constraints when married. For men: $c_{m} / z=\left(1-\tau_{m}\right) w_{m} n_{m} e_{m}+\pi_{m}+l$. For women: $c_{f} / z=\left(1-\tau_{f}\right) w_{f} n_{f} e_{f}+\pi_{f}-l$. Combining these two equations it is easy to derive the family budget constraint.
} 
Equations (11)-(13) below describe the production technology in the home sector. Equation (11) shows how home duties for men $\left(h_{m}\right)$ and women $\left(h_{f}\right)$ combine to produce output $F{ }^{18}$ Equation (12) shows that an exogenous fraction $\chi$ of the total product $F$ is allocated to a public household good $H$ (note that $H$ is non-rival and enters into the utility function of both spouses in equation (9)). An example of this good is the utility of kids. A fraction $1-\chi$ of the total product $F$ is allocated to a private household good (e.g. who eats a larger fraction of a home made meal). As equation (13) shows, since this good is private, the couple must decide how to allocate it between the two spouses. In other words, the exogenous parameter $\chi \in(0,1]$ measures the degree of non-rivalry in the consumption of home goods.

$$
\begin{gathered}
F \leq \frac{\kappa_{m}}{\alpha} h_{m}^{\alpha}+\frac{\kappa_{f}}{\alpha} h_{f}^{\alpha} \\
H \leq \chi F \\
H_{m}+H_{f} \leq(1-\chi) F
\end{gathered}
$$

Finally, equations (14) and (15) are the participation constraints, where $U_{i}^{s}$ is the value function of the program given by equations (5)-(7).

$$
\begin{gathered}
U_{m} \geq U_{m}^{s} \\
U_{f} \geq U_{f}^{s}
\end{gathered}
$$

\section{Solution of the Model}

This Section presents the solution of the model for given tax schedules. In Section 5 we discuss the comparative statics of the model. We solve the model backwards.

\subsection{Solution of the Marriage Game}

The first order conditions of the problem (8)-(15) are:

$$
\begin{gathered}
c_{m}: c_{m}=z\left(\left(1-\tau_{m}\right) w_{m} n_{m} e_{m}+\left(1-\tau_{f}\right) w_{f} n_{f} e_{f}+\pi_{m}+\pi_{f}\right)-c_{f} \\
c_{f}: \frac{\gamma}{U_{m}-U_{m}^{s}}=\frac{1-\gamma}{U_{f}-U_{f}^{s}}
\end{gathered}
$$

\footnotetext{
${ }^{18}$ The assumption that the marginal products in the home sector are independent from each other is an important one as it simplifies the solution of the model in a number of ways. First, the solution for home duties is interior and spouses do not specialize fully. Specialization certainly exists in real world families, but this would be more natural to study in a model with heterogeneous households. Second, our assumption makes career choices independent across spouses. As we discuss below such an interdependency would introduce interesting strategic elements into the model, including the possibility for multiple equilibria.
} 


$$
\begin{gathered}
n_{m}: \frac{\gamma}{U_{m}-U_{m}^{s}}\left[z\left(1-\tau_{m}\right) w_{m} e_{m}-\left(n_{m}+h_{m}\right)^{\phi}\right]=0 \\
h_{m}: \frac{\gamma}{U_{m}-U_{m}^{s}}\left[(1+\chi) \kappa_{m} h_{m}^{\alpha-1}-\left(n_{m}+h_{m}\right)^{\phi}\right]=0 \\
H_{m}: H_{m}=(1-\chi) F-H_{f} \\
n_{f}: \frac{1-\gamma}{U_{f}-U_{f}^{s}}\left[z\left(1-\tau_{f}\right) w_{f} e_{f}-\left(n_{f}+h_{f}\right)^{\phi}\right]=0 \\
h_{f}: \frac{1-\gamma}{U_{f}-U_{f}^{s}}\left[(1+\chi) \kappa_{f} h_{f}^{\alpha-1}-\left(n_{f}+h_{f}\right)^{\phi}\right]=0 \\
H_{f}: \frac{\gamma}{U_{m}-U_{m}^{s}}=\frac{1-\gamma}{U_{f}-U_{f}^{s}}
\end{gathered}
$$

together with the participation constraints, equations (14) and (15).

In the above system one equation is redundant, as equations (17) and (23) show. In other words, since preferences are quasi-linear only the sum of private consumption by gender, $c_{i}+H_{i}$, is determined. Equations (18)-(19) and (21)-(22) show that the household optimally sets the marginal product equal to the marginal disutility of working time in every sector. As these conditions show, for a predetermined choice of career $e_{i}$, bargaining power (explicit, $\gamma$, or implicit, $\left.U_{i}^{s}\right)$ does not affect the allocation of time across genders and sectors. In the absence of transaction costs and without wealth effects on labor supply (because of the quasi-linearity in consumption), the Coase Theorem applies. The household maximizes the "marital pie" by allocating time according to the first best level. Distributional issues arising from uneven bargaining power are settled efficiently by appropriate side payments that take the form of private market consumption or private household consumption $\left(c_{i}+H_{i}\right)$. However, as we show below, bargaining power affects the pre-marital choice of career $e_{i}$. Because $e_{i}$ affects the allocation of time across genders and sectors, in the end who has the bargaining power becomes relevant for the organization of the family and ultimately for fiscal policy. The Proposition below presents the solution of the marriage game.

Proposition 1. Solution of the Marriage Game: For given tax system $\tau_{i}$ and $\pi_{i}$, and career $e_{i}$, the marriage game produces the following allocations. The amount of home duties for every spouse $i=m, f$ is:

$$
h_{i}=\left(\frac{(1+\chi) \kappa_{i}}{z\left(1-\tau_{i}\right) w_{i} e_{i}}\right)^{\frac{1}{1-\alpha}}
$$

The total output of home goods, the production of the public good and the share of the private household good allocated to men are:

$$
F=\frac{\kappa_{m} h_{m}^{\alpha}}{\alpha}+\frac{\kappa_{f} h_{f}^{\alpha}}{\alpha}
$$




$$
\begin{gathered}
H=\chi F \\
H_{m}=(1-\chi) F-H_{f}
\end{gathered}
$$

Hours of market work for every spouse, gross market income for every spouse and total family income are given by:

$$
\begin{gathered}
n_{i}=\left(z\left(1-\tau_{i}\right) w_{i} e_{i}\right)^{\frac{1}{\phi}}-h_{i} \\
y_{i}=\left(1-\tau_{i}\right) w_{i} n_{i} e_{i}+\pi_{i} \\
y=y_{m}+y_{f}
\end{gathered}
$$

The allocation of total private consumption of market goods $\left(c_{i}\right)$ and household goods $\left(H_{i}\right)$ between married men and women is given by:

$$
\begin{aligned}
& c_{m}+H_{m}=\gamma z y+(\gamma-(1-\gamma) \chi) F-\gamma \frac{\left(n_{f}+h_{f}\right)^{1+\phi}}{1+\phi}+(1-\gamma) \frac{\left(n_{m}+h_{m}\right)^{1+\phi}}{1+\phi}-\gamma U_{f}^{s}+(1-\gamma) U_{m}^{s} \\
& c_{f}+H_{f}=(1-\gamma) z y+(1-\gamma-\gamma \chi) F+\gamma \frac{\left(n_{f}+h_{f}\right)^{1+\phi}}{1+\phi}-(1-\gamma) \frac{\left(n_{m}+h_{m}\right)^{1+\phi}}{1+\phi}+\gamma U_{f}^{s}-(1-\gamma) U_{m}^{s}
\end{aligned}
$$

The allocation of utilities (net of career costs $C\left(e_{i}\right)$ ) between married men and women is given by:

$$
\begin{gathered}
U_{m}=\gamma z y+\gamma(1+\chi) F-\gamma U_{f}^{s}+(1-\gamma) U_{m}^{s}-\frac{\gamma}{1+\phi}\left(\left(n_{m}+h_{m}\right)^{1+\phi}+\left(n_{f}+h_{f}\right)^{1+\phi}\right) \\
U_{f}=(1-\gamma) z y+(1-\gamma)(1+\chi) F+\gamma U_{f}^{s}-(1-\gamma) U_{m}^{s}-\frac{1-\gamma}{1+\phi}\left(\left(n_{m}+h_{m}\right)^{1+\phi}+\left(n_{f}+h_{f}\right)^{1+\phi}\right)
\end{gathered}
$$

The solution for home duties, home production, labor market hours, market consumption and utility for singles is given by:

$$
\begin{aligned}
h_{i}^{s}= & \left(\frac{\kappa_{i}}{\left(1-\tau_{i}\right) w_{i} e_{i}}\right)^{\frac{1}{1-\alpha}} \\
& H_{i}^{s}=\frac{\kappa_{i}\left(h_{i}^{s}\right)^{\alpha}}{\alpha} \\
n_{i}^{s}= & \left(\left(1-\tau_{i}\right) w_{i} e_{i}\right)^{\frac{1}{\phi}}-h_{i}^{s} \\
c_{i}^{s}= & \left(1-\tau_{i}\right) w_{i} n_{i}^{s} e_{i}+\pi_{i} \\
U_{i}^{s}=c_{i}^{s}+ & H_{i}^{s}-\frac{1}{1+\phi}\left(n_{i}^{s}+h_{i}^{s}\right)^{1+\phi}
\end{aligned}
$$

These solutions are obtained by solving the system of first order conditions for the married couple, equations (16)-(23), and the corresponding conditions for singles. We note that the participation constraints hold at optimum and the couple always decides to marry for any tax policy, i.e. $U_{i} \geq U_{i}^{s}$ (see Appendix A.1 for the proof). The reason is that the economies of scale $(z>1)$ and the public provision of household goods $(\chi>0)$ enlarge the "marital pie." Therefore, both spouses can get more utility than in their respective outside options. 


\subsection{Optimal Career}

Since marriage is optimal, expected utility net of career costs in equation (2) equals utility in the marriage, $\Phi_{i}=U_{i} \cdot{ }^{19}$ Spouse $i$ chooses a career anticipating the Nash bargaining solution:

$$
\max _{e_{i}} \Omega_{i}=U_{i}\left(e_{i}\right)-C\left(e_{i}\right)
$$

The first order condition is: ${ }^{20}$

$$
\frac{\partial U_{i}\left(e_{i}\right)}{\partial e_{i}}=C^{\prime}\left(e_{i}\right)
$$

The intuition for the career choice can be understood by looking at the derivative of the utility function $U_{i}$ in Proposition 1 with respect to $e_{i}$. Consider the case of men. Choosing a higher-wage career increases income when married. This effect is:

$$
\frac{\partial\left(\gamma z y_{m}\right)}{\partial e_{m}}=\gamma z\left(1-\tau_{m}\right) w_{m} n_{m}\left(1+\frac{1}{\phi}+\left(\frac{1}{\phi}+\frac{1}{1-\alpha}\right) \frac{h_{m}}{n_{m}}\right)>0
$$

Second, choosing a higher-wage career decreases the output produced at home. This effect is:

$$
\frac{\partial(\gamma(1+\chi) F)}{\partial e_{m}}=-\gamma(1+\chi) \frac{\kappa_{m} h_{m}^{\alpha}}{e_{m}} \frac{1}{1-\alpha}<0
$$

Third, choosing a higher-wage career increases total work $(n+h)$ and therefore it increases the disutility of work:

$$
\frac{\partial\left(-\frac{\gamma}{1+\phi}\left(n_{m}+h_{m}\right)^{1+\phi}\right)}{\partial e_{m}}=-\frac{\gamma}{\phi} \frac{\left(n_{m}+h_{m}\right)^{1+\phi}}{e_{m}}<0
$$

Fourth, choosing a higher-wage career increases men's outside option:

$$
\frac{\partial\left((1-\gamma) U_{m}^{s}\right)}{\partial e_{m}}=(1-\gamma)\left(1-\tau_{m}\right) w_{m} n_{m}^{s}>0
$$

Adding equations (26)-(29) and using the first order conditions (18) and (19) to cancel off terms, we obtain the total effect of a career on men's utility. A similar reasoning applies for the case of women. We summarize the choice of optimal career in the Proposition below. ${ }^{21}$

\footnotetext{
${ }^{19}$ We discuss below some aspects of GBT in a world with singles. See Guner, Kaygusuz and Ventura (2010) for an interesting dynamic taxation model with an active participation decision, which is calibrated to match the share of married vs. singles in the US.

${ }^{20}$ Below we show that when the elasticity of the marginal cost with respect to the career, $E$, exceeds the elasticity of labor supply of married, the function $\Omega_{i}$ is strictly concave in $e_{i}$.

${ }^{21}$ The first order condition for spouse $i$ does not involve $e_{j}$. Thus the "best response functions" are flat and the equilibrium is unique. This feature of the model follows from the assumptions: (i) lack of wealth effects in labor supply; (ii) independent marginal products in home and market production; (iii) marriage being optimal in equilibrium. If preferences were not quasi-linear, the allocation of consumption across spouses would affect labor supply, which introduces an interdependence in the choice of careers (similarly when the marginal product of one spouse depends on the work of the other spouse). Careers may also become interrelated when a random preference shock in the utility of marriage makes the probability of marriage less than one. While the first two points are mostly technical and we abstract from these for analytical tractability, the last one is an interesting extension because our model does not allow for singles in equilibrium and thus it does not take into account possible distortions in the marriage market. We discuss this point in more detail in the Conclusion.
} 
Proposition 2. Optimal Career: The following first order conditions characterize the optimal choice of careers:

$$
\begin{gathered}
\frac{\partial U_{m}}{\partial e_{m}}=\left(1-\tau_{m}\right) w_{m}\left(z \gamma n_{m}+(1-\gamma) n_{m}^{s}\right)=\left(1-\tau_{m}\right) w_{m} n_{m}\left(z \gamma+(1-\gamma) \Delta_{m}\right)=C^{\prime}\left(e_{m}\right) \\
\frac{\partial U_{f}}{\partial e_{f}}=\left(1-\tau_{f}\right) w_{f}\left(z(1-\gamma) n_{f}+\gamma n_{f}^{s}\right)=\left(1-\tau_{f}\right) w_{f} n_{f}\left(z(1-\gamma)+\gamma \Delta_{f}\right)=C^{\prime}\left(e_{f}\right)
\end{gathered}
$$

where the labor supply of singles relative to married is defined as:

$$
\Delta_{i}:=\frac{n_{i}^{s}}{n_{i}}
$$

Pursuing a higher-wage career increases utility because it increases income when married. A higher-wage career also increases income when single which matters because it determines the implicit bargaining power of spouse $i$ and building a career offers outside options which translate into a higher level of utility when married. For men, these two effects are weighted by $z \gamma n_{m}$ and $(1-\gamma) n_{m}^{s}$, where $z$ denotes the economies of scale parameter. The weight on the marriage effect is multiplied by $z$ because married people enjoy economies of scale. The weight on the marriage effect increases with the explicit bargaining power of men $(\gamma)$ and with the labor supply of married men $\left(n_{m}\right)$. The weight on the effect of singles decreases with the explicit bargaining power of men $(\gamma)$ and increases with the labor supply of single men $\left(n_{m}^{s}\right)$. As equation (30) shows, the optimal career equalizes the benefit of pursuing a higher-wage career to the costs associated with the additional time and effort to acquire skills and the increased stress in the market. Similar effects apply in the case of women.

\section{Gendered Equilibria}

We analyze two broad cases. In the first one women have a comparative advantage in home production:

$$
\frac{\kappa_{f}}{\kappa_{m}}>\frac{w_{f}}{w_{m}}
$$

This case emerges under a variety of circumstances, such as biological differences in productivity at home $\left(\kappa_{f}>\kappa_{m}\right.$ with $\left.w_{m}=w_{f}\right)$ or differences in market wages $\left(w_{m}>w_{f}\right.$ with $\kappa_{m}=\kappa_{f}$ ) as a result of market productivity differences or gender discrimination, or a combination of these. Even though the sectoral allocation of time across genders depends only on the comparative advantage, who has the absolute advantage is relevant for tax policy because absolute advantages $\left(w_{m}>w_{f}\right.$ or $\left.\kappa_{f}>\kappa_{m}\right)$ determine the final distribution of utilities across spouses. We discuss this point in more detail in Section 6. 
The second case is when, for cultural or historical reasons from a period of time where physical power mattered, men have higher bargaining power than women:

$$
\gamma>1 / 2
$$

Assumption 1. Parameters: The parameters $z$ and $\chi$ satisfy:

$$
(1+\chi)>z^{1+\frac{1-\alpha}{\phi}}>z>\Delta_{i}(z, \chi)>1
$$

where $\Delta_{i}$ is the labor supply of singles relative to married as defined in equation (32).

First, we note that $\Delta_{i}$ depends on $z$ and $\chi$. In Appendix A.2 we prove that there is an area of $z$ 's and $\chi$ 's such that condition (35) in Assumption 1 holds.

Assumption 1 implies that singles work more than the married in the market (i.e. $\Delta_{i}>1$ ) and that the married take more home duties than the singles (i.e. $1+\chi>z$ ). ${ }^{22}$ The inequality $(1+\chi)>z^{1+\frac{1-\alpha}{\phi}}$ is a necessary condition for $\Delta_{i}>1$. The inequality $z>\Delta_{i}$ has the following economic interpretation. When spouse $i$ receives a positive income shock, $j$ 's utility increases because of the sharing of resources in the marriage. But at the same time, $j$ 's utility decreases as spouse $i$ acquires implicit bargaining power and appropriates a larger share of the increased family income. When economies of scale are important with respect to the labor supply of singles (relative to married), the first effect dominates and both spouses benefit from the positive income shock (although not equally). As it becomes clear below, the inequality $z>\Delta_{i}$ is crucial for our results.

The following Proposition highlights several implications of our model which are consistent with the evidence (see e.g. Burda, Hamermesh and Weil, 2007).

Proposition 3. Gendered Equilibria: Suppose that one of the three cases holds: (i) $\gamma>$ $1 / 2$ with $w_{m}=w_{f}$ and $\kappa_{m}=\kappa_{f}$; (ii) $w_{m}>w_{f}$ with $\gamma=1 / 2$ and $\kappa_{m}=\kappa_{f}$; (iii) $\kappa_{f}>\kappa_{m}$ with $\gamma=1 / 2$ and $w_{m}=w_{f} \cdot{ }^{23}$ Suppose also that Assumption 1 holds. Holding constant the marginal tax rates at some arbitrary level $\tau=\tau_{m}=\tau_{f}$, we obtain the following results:

1. Men pursue higher-wage careers than women: $e_{m}>e_{f}$.

2. Men take less home duties than women: $h_{m}<h_{f}$ and $h_{m}^{s}<h_{f}^{s}$.

\footnotetext{
${ }^{22}$ This assumption seems consistent with the evidence of Burda, Hamermesh and Weil (2007) for the US (2003) and for Germany (2001-2002).

${ }^{23}$ Our results could hold when some of the equalities fail or under a combination of (i), (ii) and (iii) but for expository reasons we restrict attention to the three extreme cases that isolate the source of the gendered equilibrium.
} 
3. Men work more in the market than women: $n_{m}>n_{f}$ and $n_{m}^{s}>n_{f}^{s}$.

4. Men have a higher marginal product than women in both sectors: $q_{m}>q_{f}$ and $q_{m}^{s}>q_{f}^{s}$.

5. Marriage amplifies the gender gap in home duties: $h_{f}-h_{m}>h_{f}^{s}-h_{m}^{s}$.

6. Marriage amplifies the gender gap in market work: $n_{m}-n_{f}>n_{m}^{s}-n_{f}^{s}$.

7. Men have a lower wage elasticity of labor supply than women: $\epsilon_{n_{m}, w_{m}}<\epsilon_{n_{f}, w_{f}}$ and $\epsilon_{n_{m}, w_{m}}^{s}<\epsilon_{n_{f}, w_{f}}^{s}$.

8. Singles have a lower wage elasticity of labor supply than married: $\epsilon_{n_{i}, w_{i}}^{s}<\epsilon_{n_{i}, w_{i}}$ for $i=m, f$.

9. Marriage amplifies the gender gap in wage elasticities of labor supply: $\epsilon_{n_{f}, w_{f}}-\epsilon_{n_{m}, w_{m}}>$ $\epsilon_{n_{f}, w_{f}}^{s}-\epsilon_{n_{m}, w_{m}}^{s}$.

10. Men have a lower wage elasticity of career than women: $\epsilon_{e_{m}, w_{m}}<\epsilon_{e_{f}, w_{f}}$ (for the case of $\gamma>1 / 2$ this is subject to the additional Assumption 2 presented below).

We now show how to derive Proposition 3 and give the intuition of these comparative statics. Consider first the case of $\gamma>1 / 2$. The key step is to show how for equal marginal tax rates $\left(\tau_{m}=\tau_{f}\right)$, equal exogenous wages $\left(w_{m}=w_{f}\right)$ and equal inherent productivities in the home sector $\left(\kappa_{m}=\kappa_{f}\right)$, men choose higher-wage careers than women, $e_{m}>e_{f}$. To prove this result, we note that the first order conditions for the optimal career, equations (30) and (31), and the solution for labor supply in Proposition 1 imply the symmetric solution $e_{m}=e_{f}$ when $\gamma=1 / 2$. Differentiating implicitly men's first order condition for the optimal career, equation (30), and using Assumption 1 (note that $z>\Delta_{i}$ is necessary and sufficient):

$$
\frac{\partial e_{m}}{\partial \gamma} \propto \frac{\partial^{2} U_{m}}{\partial e_{m} \partial \gamma}=\left(1-\tau_{m}\right) w_{m} n_{m}\left(z-\Delta_{m}\right)>0
$$

For women an analogous argument shows that $e_{f}$ decreases in $\gamma$. As a result, when $\gamma>1 / 2$ we take $e_{m}>e_{f}$. The intuition is that higher-wage careers enlarge the size of the "marital pie" to be divided between spouses. The stronger are the economies of scale, the larger is the increase of the total pie. When men have more bargaining power, they anticipate to appropriate a larger share of the enlarged pie and therefore their incentive to pursue higherwage careers increases. But choosing a higher-wage career before marriage also increases the value of remaining single, thus increasing the implicit bargaining power. ${ }^{24}$ As a result,

\footnotetext{
${ }^{24}$ Pollak (2007) argues convincingly that the wage rate and implicitly the level of human capital should determine the outside option of a spouse. Our model addresses this concern in the literature.
} 
women tend to choose a higher-wage career to offset their lower explicit bargaining power. The marriage effect dominates the outside option effect when economies of scale are large with respect to the labor market participation of singles relative to married $\left(z>\Delta_{i}\right)$. The latter matters because the value of the outside option increases when, off-equilibrium, singles threat to work more in the market.

Because $e_{m}>e_{f}$, the solution to the Nash bargaining program presented in Proposition 1 implies that men take less home duties than women, $h_{m}<h_{f}$ and $h_{m}^{s}<h_{f}^{s}$. In our model, home duties and participation in the market are Beckerian (1985) substitutes. To see this, consider the first order conditions (18) and (21) for the optimal supply of labor for married couples:

$$
q_{i}:=\left(n_{i}+h_{i}\right)^{\phi}=z\left(1-\tau_{i}\right) w_{i} e_{i}
$$

This condition shows how, for given level of taxes and effective wages, market hours offset one to one home hours. ${ }^{25}$ It follows that if men assume less home duties, then they work more at the market $n_{m}>n_{f}$, both because of a higher $e_{m}$ and because of a lower $h_{m}$. Equation (37) also shows that men have a higher marginal product than women in every sector, $q_{m}>q_{f}$, a result that follows from the assumption that the home sector is subject to decreasing returns to scale. A similar argument applies for the case of singles, $n_{m}^{s}>n_{f}^{s}$ and $q_{m}^{s}>q_{f}^{s}$.

Next, we show how the marriage decision amplifies gender differences in the allocation of time. This result is consistent with the time use evidence in Burda, Hamermesh and Weil (2007). For the amount of home duties, using the solutions in Proposition 1 we obtain:

$$
h_{f}-h_{m}=\left(\frac{1+\chi}{z}\right)^{\frac{1}{1-\alpha}}\left(h_{f}^{s}-h_{m}^{s}\right)
$$

Using Assumption 1, the term $[(1+\chi) / z]^{1 /(1-\alpha)}$ is greater than unity. Therefore, it amplifies the difference in the amount of home duties across genders, i.e. $h_{f}-h_{m}>h_{f}^{s}-h_{m}^{s}$. For the working time in the market we have:

$$
n_{m}-n_{f}=z^{\frac{1}{\phi}}\left(n_{m}^{s}-n_{f}^{s}\right)+\left[\left(h_{f}-h_{m}\right)-z^{\frac{1}{\phi}}\left(h_{f}^{s}-h_{m}^{s}\right)\right]
$$

Because $z>1$ and because the bracketed term in the right-hand side of (39) is positive, $n_{m}-n_{f}>n_{m}^{s}+n_{f}^{s} .{ }^{26}$ Intuitively, the gender gap in the allocation of time is amplified inside the marriage because the economies of scale in private consumption and the public provision

\footnotetext{
${ }^{25}$ Aguiar and Hurst (2007) and Burda, Hamermesh and Weil (2007) document that in developed countries like the US, men and women take a similar amount of total work. In other words, higher home work, rather an increased time spent in leisure, tends to primarily offset a lower market participation.

${ }^{26}$ That the bracketed term is positive follows by substituting $h_{f}-h_{m}$ from equation (38) into the bracketed term of equation (39) and then using Assumption 1.
} 
of home goods, which take place only when married, make the returns to partial specialization higher for married people than for singles.

The elasticity of labor supply is derived as follows. Using the first order conditions for the labor supply of married, equations (18) and (21), we take:

$$
\frac{\partial n_{i}}{\partial w_{i}}+\frac{\partial h_{i}}{\partial w_{i}}=\frac{1}{\phi}\left(z\left(1-\tau_{i}\right) e_{i}\right)^{\frac{1}{\phi}} w_{i}^{\frac{1}{\phi}-1}
$$

The solution for home duties in Proposition 1 yields $\partial h_{i} / \partial w_{i}=-[1 /(1-\alpha)]\left(h_{i} / w_{i}\right)$. Multiplying equation (40) by $w_{i} / n_{i}$ and using the expression for $\partial h_{i} / \partial w_{i}$ we obtain:

$$
\epsilon_{n_{i}, w_{i}}=\frac{\partial n_{i}}{\partial w_{i}} \frac{w_{i}}{n_{i}}=\frac{1}{\phi} \frac{\left(z\left(1-\tau_{i}\right) w_{i} e_{i}\right)^{\frac{1}{\phi}}}{n_{i}}+\frac{h_{i}}{n_{i}} \frac{1}{1-\alpha}
$$

Finally, using equation (37), we obtain an expression for the wage elasticity of labor supply as a function of the ratio of home duties over market work:

$$
\epsilon_{n_{i}, w_{i}}=\frac{1}{\phi}+\left(\frac{1}{\phi}+\frac{1}{1-\alpha}\right) \frac{h_{i}}{n_{i}}
$$

For the case of singles a similar derivation yields:

$$
\epsilon_{n_{i}, w_{i}}^{s}=\frac{1}{\phi}+\left(\frac{1}{\phi}+\frac{1}{1-\alpha}\right) \frac{h_{i}^{s}}{n_{i}^{s}}
$$

Equations (42) and (43) show that women's wage elasticity of labor supply is higher since women take more home duties and work less than men in the market. Moreover, the elasticity is lower for singles than for married because by Assumption 1 we have $h_{i}^{s} / n_{i}^{s}<h_{i} / n_{i}$.

The model also predicts that the decision to marry amplifies the gender elasticity difference, $\epsilon_{n_{f}, w_{f}}-\epsilon_{n_{m}, w_{m}}>\epsilon_{n_{f}, w_{f}}^{s}-\epsilon_{n_{m}, w_{m}}^{s}$, which is consistent with the fact that the gender gap in the labor supply elasticities seems to be driven by married women (Blau and Kahn, 2007). The intuition for the result that marriage amplifies the gender gap in labor supply elasticities follows from the fact that the elasticity of labor supply is increasing in the ratio of home duties to market work, in conjunction with the result that marriage amplifies the gender differences in market work and home duties. The proof is presented in Appendix A.3.

Finally, consider the elasticity of men's and women's career decision. For men and women we obtain respectively (see Appendix A.4 for the derivation): ${ }^{27}$

$$
\epsilon_{e_{m}, w_{m}}=\frac{\gamma z\left(1+\epsilon_{n_{m}, w_{m}}\right)+(1-\gamma) \Delta_{m}\left(1+\epsilon_{n_{m}, w_{m}}^{s}\right)}{\gamma z\left(E-\epsilon_{n_{m}, w_{m}}\right)+(1-\gamma) \Delta_{m}\left(E-\epsilon_{n_{m}, w_{m}}^{s}\right)}
$$

\footnotetext{
${ }^{27}$ These formulas follow from an application of the Implicit Function Theorem and show that the objective function $\Omega_{i}=U_{i}\left(e_{i}\right)-C\left(e_{i}\right)$ is strictly concave in $e_{i}$ whenever $E$ exceeds the elasticities of labor supply. In this case the denominators in equations (44) and (45) are positive.
} 


$$
\epsilon_{e_{f}, w_{f}}=\frac{(1-\gamma) z\left(1+\epsilon_{n_{f}, w_{f}}\right)+\gamma \Delta_{f}\left(1+\epsilon_{n_{f}, w_{f}}^{s}\right)}{(1-\gamma) z\left(E-\epsilon_{n_{f}, w_{f}}\right)+\gamma \Delta_{f}\left(E-\epsilon_{n_{f}, w_{f}}^{s}\right)}
$$

where $E=C^{\prime \prime} e / C^{\prime}$ denotes the elasticity of the marginal cost of careers. Intuitively, the decision to pursue a career precedes the marriage decision. As a result, the elasticity of pursuing a career in the market sector becomes a weighted average of the elasticity of labor supply when married and the elasticity of labor supply when single.

As we discuss in the next Section and prove in Appendix A.7, the elasticity of careers is increasing in the marginal tax rate $\tau_{i}$, i.e. it is decreasing in the effective wage $w_{i} e_{i}$ and increasing in the home productivity parameter $\kappa_{i}$, for any $\gamma$. Therefore, when gender differences derive solely from comparative advantage, $\epsilon_{e_{m}, w_{m}}<\epsilon_{e_{f}, w_{f}}$. In anticipation of a higher labor supply elasticity when married or single, women's career decision becomes more sensitive to exogenous changes in the wage.

For the case of $\gamma>1 / 2$, there are two opposing effects. The fact that men choose higherwage careers than women $\left(e_{m}>e_{f}\right)$ implies, similarly to the comparative advantage case, that $\epsilon_{e_{m}, w_{m}}<\epsilon_{e_{f}, w_{f}}$. But in this case there is also a compositional effect because, as equations (44) and (45) show, as $\gamma$ increases, men's elasticity puts more weight on the labor supply elasticity of married, while women's elasticity puts more weight on the labor supply elasticity of singles. Because singles have a less elastic labor supply than married, this effect tends to increase $\epsilon_{e_{m}, w_{m}}$ and to decrease $\epsilon_{e_{f}, w_{f}}$. For the case of $\gamma>1 / 2$, an intuitive sufficient condition for $\epsilon_{e_{m}, w_{m}}<\epsilon_{e_{f}, w_{f}}$ is that the labor supply of married men is less elastic than the labor supply of single women. ${ }^{28}$

Assumption 2. Married Men vs. Single Women: Married men's labor supply is less elastic than single women's labor supply: $\epsilon_{n_{m}, w_{m}}<\epsilon_{n_{f}, w_{f}}^{s}$.

We do not solve explicitly for the parameters that satisfy this condition because the ratios $h_{m} / n_{m}$ and the $h_{f}^{s} / n_{f}^{s}$ depend on the unspecified cost function $C(e)$. Rather, we cite some evidence that points out that this assumption is likely to be satisfied. Burda, Hamermesh and Weil (2007) find $h_{m} / n_{m}=0.54<h_{f}^{s} / n_{f}^{s}=0.97$ for the US (2003) and $h_{m} / n_{m}=0.64<h_{f}^{s} / n_{f}^{s}=1.50$ for Germany (2001-2002). According to equations (42) and (43) this implies $\epsilon_{n_{m}, w_{m}}<\epsilon_{n_{f}, w_{f}}^{s}$. And in fact, Blau and Kahn (2007) estimate wage elasticities for single women that range from 0.43 to 0.59 in 1980 and then fall to 0.15 to 0.28 by 2000 . For married men, the authors find wage elasticities that range from 0.01 to 0.07 in 1980 and from 0.05 to 0.10 in 2000 .

\footnotetext{
${ }^{28}$ This follows from the following observation. Since $\epsilon_{n_{m}, w_{m}}>\epsilon_{n_{m}, w_{m}}^{s}$, the upper bound for $\epsilon_{e_{m}, w_{m}}$ must be $\left(1+\epsilon_{n_{m}, w_{m}}\right) /\left(E-\epsilon_{n_{m}, w_{m}}\right)$. Similarly, the lower bound for $\epsilon_{e_{f}, w_{f}}$ is $\left(1+\epsilon_{n_{f}, w_{f}}^{s}\right) /\left(E-\epsilon_{n_{f}, w_{f}}^{s}\right)$. These cases are obtained under $\gamma=1$.
} 
To save space we do not analyze separately the cases of $w_{m}>w_{f}$ and $\kappa_{f}>\kappa_{m}$. We note that in these cases there is the direct, exogenous effect of comparative advantage but there is also an indirect, endogenous effect coming from the fact that $e_{m}>e_{f}$. These effects can be analyzed easily by following the same arguments as for $\gamma>1 / 2$ case. The only exception is the result $\epsilon_{e_{m}, w_{m}}<\epsilon_{e_{f}, w_{f}}$ for which, as discussed above, Assumption 2 is not necessary.

\section{Gender-Based Taxation}

The social planner chooses gender-specific linear tax schedules to maximize social welfare:

$$
\max _{\tau_{m}, \pi_{m}, \tau_{f}, \pi_{f}} W=\omega V\left(U_{m}-C\left(e_{m}\right)\right)+(1-\omega) V\left(U_{f}-C\left(e_{f}\right)\right)
$$

The function $V($.$) satisfies V^{\prime}>0$ and $V^{\prime \prime}<0$ and is symmetric across genders. ${ }^{29}$ Potential asymmetries across genders are captured by allowing $\omega \neq 1 / 2$. The problem is subject to the government's budget constraint:

$$
T_{m}+T_{f}=\tau_{m} w_{m} n_{m} e_{m}+\tau_{f} w_{f} n_{f} e_{f}-\pi_{m}-\pi_{f} \geq G
$$

With an important exception discussed below, lump sum taxes, $\pi_{i}<0$, are excluded because in this case the planner could trivially raise revenues without distortions to finance $G$. Gender-specific lump sum transfers, $\pi_{i} \geq 0$, play a non-trivial role, despite the fact that spouses can make side payments. Because the bargaining outcome depends on the utility of singles, gender-specific lump sum transfers (given also to singles) affect the distribution of consumption and utility in the marriage by changing the implicit bargaining powers. ${ }^{30}$

Attaching multiplier $\lambda$ to the government budget constraint, the first order conditions of the planning program are given by (with the definition $V_{i}^{\prime}:=V^{\prime}\left(U_{i}-C\left(e_{i}\right)\right)$ ):

$$
\begin{gathered}
\tau_{m} \geq 0: \frac{\partial U_{m}}{\partial \tau_{m}} \omega V_{m}^{\prime}-C^{\prime}\left(e_{m}\right) \frac{\partial e_{m}}{\partial \tau_{m}} \omega V_{m}^{\prime}+\frac{\partial U_{f}}{\partial \tau_{m}}(1-\omega) V_{f}^{\prime} \leq-\lambda \frac{\partial T_{m}}{\partial \tau_{m}} \\
\tau_{f} \geq 0: \frac{\partial U_{m}}{\partial \tau_{f}} \omega V_{m}^{\prime}-C^{\prime}\left(e_{f}\right) \frac{\partial e_{f}}{\partial \tau_{f}}(1-\omega) V_{f}^{\prime}+\frac{\partial U_{f}}{\partial \tau_{f}}(1-\omega) V_{f}^{\prime} \leq-\lambda \frac{\partial T_{f}}{\partial \tau_{f}} \\
\pi_{m} \geq 0: \frac{\partial U_{m}}{\partial \pi_{m}} \omega V_{m}^{\prime}+\frac{\partial U_{f}}{\partial \pi_{m}}(1-\omega) V_{f}^{\prime} \leq-\lambda \frac{\partial T_{m}}{\partial \pi_{m}}
\end{gathered}
$$

\footnotetext{
${ }^{29}$ The concavity of the $V($.$) function introduces utilitarian motives in government's objective despite the$ lack of curvature in the primitive utility function.

${ }^{30}$ In the unitary model or in a model in which the couple maximizes a weighted average of utilities without reference to the outside options of the spouses, the pooling of resources implies that only the sum of the transfers $\pi_{m}+\pi_{f}$ is determined and not the gender-specific transfer $\pi_{i}$. Lundberg, Pollak and Wales (1997) discuss a natural experiment in the UK which strongly rejects this implication of the unitary model.
} 


$$
\begin{gathered}
\pi_{f} \geq 0: \frac{\partial U_{m}}{\partial \pi_{f}} \omega V_{m}^{\prime}+\frac{\partial U_{f}}{\partial \pi_{f}}(1-\omega) V_{f}^{\prime} \leq-\lambda \frac{\partial T_{f}}{\partial \pi_{f}} \\
\lambda \geq 0: \tau_{m} w_{m} n_{m} e_{m}+\tau_{f} w_{f} n_{f} e_{f}-\pi_{m}-\pi_{f} \geq G
\end{gathered}
$$

Equations (48) and (49) show that in an interior equilibrium $\left(\tau_{i}>0\right)$ the planner equalizes the social marginal utility cost of higher marginal tax rates to the social value of an extra dollar of revenues raised by higher taxes for every gender $i=m, f$. Equations (50) and (51) are the corresponding conditions for the lump sum transfers and equation (52) is the budget constraint. Because utility is decreasing in marginal tax rates and increasing in transfers, the budget constraint binds at optimum and $\lambda>0$.

We also consider the case of "purely redistributive" lump sum transfers, namely we allow for a lump sum tax to spouse $i, \pi_{i}<0$, as long as this is not used to finance $G$ without distortions. Instead, the revenue raised by this tax is given to spouse $j$ as a lump sum transfer. In other words, we leave the sign of $\pi_{i}$ unrestricted but we require that $\pi_{m}+\pi_{f}=0$. This case is interesting because, as we argue below, it shows the desirability of GBT on efficiency grounds only, that is after all distributional concerns have been resolved efficiently by the society.

First, we derive the response of welfare and revenues to taxes. Second, we present the solution for the lump sum transfers as a function of society's desire to redistribute wealth across genders. Third, we prove the optimality of GBT with $\tau_{m}>\tau_{f}$ when society's marginal cost of taxing men is equal to (or smaller than) society's marginal cost of taxing women. Finally, we discuss some further implications of GBT.

\subsection{Welfare and Tax Revenues}

Using the solution for $U_{i}^{s}$ in Proposition 1, we obtain: ${ }^{31}$

$$
\begin{gathered}
\frac{\partial U_{i}^{s}}{\partial \tau_{i}}=-w_{i} n_{i} e_{i}+\left(1-\tau_{i}\right) w_{i} n_{i} \frac{\partial e_{i}}{\partial \tau_{i}}<0 \\
\frac{\partial U_{i}^{s}}{\partial \pi_{i}}=1
\end{gathered}
$$

Using the solution for men's utility in Proposition 1, the first order conditions (16)-(23) and the response of the outside option with respect to taxes in equations (53) and (54) we obtain:

$$
\frac{\partial U_{m}}{\partial \tau_{m}}=-\left(\gamma z+(1-\gamma) \Delta_{m}\right) w_{m} e_{m} n_{m}\left(1-\frac{1-\tau_{m}}{\tau_{m}} \epsilon_{e_{m}, \tau_{m}}\right)<0
$$

\footnotetext{
${ }^{31}$ The Envelope Theorem does not apply strictly because as of the third stage of the game $e_{i}$ is predetermined but from the planner's point of view $e_{i}$ is elastic.
} 


$$
\frac{\partial U_{m}}{\partial \pi_{m}}=\gamma z+(1-\gamma)>0
$$

Higher marginal tax rates decrease income both inside and outside the marriage. These effects are weighted by $\gamma z$ and $(1-\gamma) \Delta_{m}$ respectively. In addition, higher taxes distort the incentive to choose a higher-wage career and this cost increases with (the absolute value of) the elasticity of a career with respect to taxes, $\epsilon_{e_{m}, \tau_{m}}$. A lump sum transfer increases utility by $z$ inside the marriage and by 1 when single. These effects are weighted with $\gamma$ and $1-\gamma$ respectively. The effects of higher women's taxes on men's utility are:

$$
\begin{gathered}
\frac{\partial U_{m}}{\partial \tau_{f}}=-\gamma\left(z-\Delta_{f}\right) w_{f} e_{f} n_{f}\left(1-\frac{1-\tau_{f}}{\tau_{f}} \epsilon_{e_{f}, \tau_{f}}\right)<0 \\
\frac{\partial U_{m}}{\partial \pi_{f}}=\gamma(z-1)>0
\end{gathered}
$$

Men's utility decreases with women's taxes because total family income decreases and spouses share resources. Men's utility increases with women's taxes because women's outside option deteriorates which implies an increase in the implicit bargaining power of men who appropriate a larger share of family's income. As explained in Assumption 1, when economies of scale are relatively important $\left(z>\Delta_{f}\right)$, the first effect dominates and men's utility decreases with women's marginal tax rate. A similar intuition holds for the lump sum transfer. For women the corresponding effects are:

$$
\begin{gathered}
\frac{\partial U_{f}}{\partial \tau_{f}}=-\left((1-\gamma) z+\gamma \Delta_{f}\right) w_{f} e_{f} n_{f}\left(1-\frac{1-\tau_{f}}{\tau_{f}} \epsilon_{e_{f}, \tau_{f}}\right)<0 \\
\frac{\partial U_{f}}{\partial \pi_{f}}=(1-\gamma) z+\gamma>0 \\
\frac{\partial U_{f}}{\partial \tau_{m}}=-\left((1-\gamma) z-(1-\gamma) \Delta_{m}\right) w_{m} e_{m} n_{m}\left(1-\frac{1-\tau_{m}}{\tau_{m}} \epsilon_{e_{m}, \tau_{m}}\right)<0 \\
\frac{\partial U_{f}}{\partial \pi_{m}}=(1-\gamma)(z-1)>0
\end{gathered}
$$

Differentiating the revenue function $T_{i}=\tau_{i} w_{i} n_{i} e_{i}-\pi_{i}$ with respect to taxes we obtain:

$$
\begin{gathered}
\frac{\partial T_{i}}{\partial \tau_{i}}=w_{i} n_{i} e_{i}+\tau_{i} w_{i} n_{i} \frac{\partial e_{i}}{\partial \tau_{i}}+\tau_{i} w_{i} e_{i}\left(\frac{\partial n_{i}}{\partial \tau_{i}}+\frac{\partial n_{i}}{\partial e_{i}} \frac{\partial e_{i}}{\partial \tau_{i}}\right) \\
\frac{\partial T_{i}}{\partial \pi_{i}}=-1
\end{gathered}
$$

Finally, for the case of purely redistributive transfers across spouses, we set $\pi=\pi_{f}$ and $\pi=-\pi_{m}$, so that a positive $\pi$ denotes a lump sum transfer from the man to the woman. Total family income does not respond to the purely redistributive transfer but the outside options change with $\pi$ and as a result the government can affect the final allocation of utilities in the marriage. It is easy to show that $\partial U_{m} / \partial \pi=-1$ and $\partial U_{f} / \partial \pi=1$. Because this is a budget-neutral redistributive policy, government's net revenues remain constant. 


\subsection{Lump Sum Transfers}

We analyze five cases. Lump sum transfers to both spouses are never optimal. If the planner favors one of the spouses extremely, then this spouse receives a lump sum transfer and faces zero marginal tax rates. Which of these cases is optimal depends on the weight $\omega$, the curvature of $V($.$) and the deeper determinant of the gendered equilibrium. In addition, we$ show how purely redistributive transfers across spouses are chosen to equalize their social marginal utilities, leaving the efficiency aspects of GBT unaffected. In Section 6.3 we analyze this case which leads to interior solutions.

\subsubsection{Lump Sum Transfers to Both Spouses: $\pi_{m}>0$ and $\pi_{f}>0$}

This case is impossible. The intuition is that the planner satisfies any redistributive motive by giving a lump sum transfer either to the man or to the woman. Giving lump sum transfers to both spouses does not improve the distribution of utilities (since the planner can always give a smaller transfer to one spouse and no transfer to the other) and creates distortions because these transfers must be financed with higher marginal tax rates. The formal proof is in Appendix A.5.

\subsubsection{Lump Sum Transfers Only to Men: $\pi_{m}>0$ and $\pi_{f}=0$}

If $\pi_{m}>0$ then $\tau_{m}=0$. Since $G+\pi_{m}>0$, it follows that the planner sets $\tau_{f}>0$. The intuition is that when the planner favors men extremely (e.g. if $\omega$ is very high), the efficient way to redistribute wealth in favor of men is to set their marginal tax rate equal to zero. Setting $\tau_{m}>0$ would increase revenues but these extra revenues (given back to men) would create more distortions. As a result, the planner uses women's marginal tax rate to finance $G$ and men's transfers. The formal proof is in Appendix A.6.

\subsubsection{Lump Sum Transfers Only to Women: $\pi_{f}>0$ and $\pi_{m}=0$}

This case is symmetric to the previous case. If society's weight on women is relatively high, then $\tau_{f}=0$ and $\tau_{m}>0$ is the efficient way to redistribute wealth in favor of women.

\subsubsection{No Lump Sum Transfers: $\pi_{f}=0$ and $\pi_{m}=0$}

This case is obtained when society's cost of raising funds is high relative to the motive to redistribute wealth:

$\lambda>\max \left\{(\gamma z+(1-\gamma)) \omega V_{m}^{\prime}+(1-\gamma)(z-1)(1-\omega) V_{f}^{\prime}, \gamma(z-1) \omega V_{m}^{\prime}+(z(1-\gamma)+\gamma)(1-\omega) V_{f}^{\prime}\right\}$ 
In this case both marginal taxes will, in general, be positive. Using the derivations in Section 6.1, we can combine the first order conditions (48) and (49) and write the following expression that determines the optimal tax treatment of the family:

$$
\begin{array}{r}
\frac{\left(\gamma z+(1-\gamma) \Delta_{m}\right) \omega V_{m}^{\prime}+(1-\gamma)\left(z-\Delta_{m}\right)\left(1+\epsilon_{e_{m}, w_{m}}\right)(1-\omega) V_{f}^{\prime}}{\gamma\left(z-\Delta_{f}\right)\left(1+\epsilon_{e_{f}, w_{f}}\right) \omega V_{m}^{\prime}+\left((1-\gamma) z+\gamma \Delta_{f}\right)(1-\omega) V_{f}^{\prime}}= \\
=\frac{1-\frac{\tau_{m}}{1-\tau_{m}}\left(\epsilon_{e_{m}, w_{m}}+\epsilon_{n_{m}, w_{m}}+\epsilon_{n_{m}, w_{m}} \epsilon_{e_{m}, w_{m}}\right)}{1-\frac{\tau_{f}}{1-\tau_{f}}\left(\epsilon_{e_{f}, w_{f}}+\epsilon_{n_{f}, w_{f}}+\epsilon_{n_{f}, w_{f}} \epsilon_{e_{f}, w_{f}}\right)}
\end{array}
$$

The optimal marginal tax rates equalize the (men to women) relative marginal cost of taxation (left-hand side) to the relative marginal revenue from increasing tax rates (righthand side). Our proof in Section 6.3 that the planner optimally sets $\tau_{m}>\tau_{f}$ applies to this case as well whenever the left-hand side of equation (65) does not exceed unity (this condition is only sufficient and not necessary). In other words, GBT with higher taxes on men is optimal when the marginal cost of taxing men is equal to (or is smaller than) the marginal cost of taxing women. More in general, in this case the solution for the marginal tax rates depends not only on the efficiency aspects of differential taxation, but also on the planner's weight on men $\omega$ and the curvature of the $V($.$) function. That is, in the absence of$ lump sum transfers, distributional considerations become important in the determination of the optimal marginal tax rates. Instead of analyzing this case which mixes distributional and efficiency considerations, we now focus on the case in which the planner can use lump sum transfers across spouses to satisfy any distributional motive efficiently.

\subsubsection{Redistributive Transfers Across Spouses: $\pi_{m}=-\pi_{f}$}

Using the results of Section 6.1 on equations (50) and (51), in this case we obtain an equalization of the social marginal utilities:

$$
\omega V_{m}^{\prime}=(1-\omega) V_{f}^{\prime}
$$

Using equation (66) on the first order conditions (48) and (49), we obtain the key condition that determines the optimal tax treatment of the family:

$$
\frac{z+(1-\gamma)\left(z-\Delta_{m}\right) \epsilon_{e_{m}, w_{m}}}{z+\gamma\left(z-\Delta_{f}\right) \epsilon_{e_{f}, w_{f}}}=\frac{1-\frac{\tau_{m}}{1-\tau_{m}}\left(\epsilon_{e_{m}, w_{m}}+\epsilon_{n_{m}, w_{m}}+\epsilon_{n_{m}, w_{m}} \epsilon_{e_{m}, w_{m}}\right)}{1-\frac{\tau_{f}}{1-\tau_{f}}\left(\epsilon_{e_{f}, w_{f}}+\epsilon_{n_{f}, w_{f}}+\epsilon_{n_{f}, w_{f}} \epsilon_{e_{f}, w_{f}}\right)}
$$

While different marginal tax rates across genders also redistribute wealth, equation (66) shows that the lump sum transfer from the one spouse to the other always adjusts optimally to equalize their social marginal utilities. 


\subsection{Optimal Gender-Based Taxation}

When the planner optimally redistributes wealth using condition (66), the slopes of the tax schedule depend only on the efficiency properties of differential taxation. Equation (67) characterizes the trade-off between the relative marginal cost of increasing men's marginal tax rate (left-hand side) versus the relative marginal revenue from taxing men on a higher marginal tax rate (right-hand side). This equation, however, does not provide an explicit solution for $\tau_{m}$ (as a function of $\tau_{f}$ ) because GBT endogenously changes the career decisions, the allocation of home duties and market work and the elasticities of labor supply. In other words, equation (67) is a fixed point problem.

To proceed, fix women's marginal tax rate at some arbitrary level $\tau_{f}=\tau>0$ and set $\tau_{m}=x+\tau$, i.e. $x \in(-\tau, 1-\tau)$ is the gender difference in the marginal tax rates. We are looking for a fixed point of equation $(67)$, call it $x(\tau)$. GBT with higher taxes for men is optimal when the fixed point satisfies $x(\tau)>0$ for all $\tau>0 .{ }^{32}$

Proposition 4. Gender-Based Taxation: Suppose that one of the three cases holds: (i) $\gamma>1 / 2$ with $w_{m}=w_{f}$ and $\kappa_{m}=\kappa_{f}$; (ii) $w_{m}>w_{f}$ with $\gamma=1 / 2$ and $\kappa_{m}=\kappa_{f}$; (iii) $\kappa_{f}>\kappa_{m}$ with $\gamma=1 / 2$ and $w_{m}=w_{f} \cdot{ }^{33}$ Under Assumptions 1 and 2, equation (66) and the regularity condition that the relative marginal cost of taxation does not exceed the relative marginal revenue of taxation at the single tax rate $(x=0)$, GBT with higher marginal tax rates on men is optimal: $x(\tau)>0$.

Assumptions 1 and 2 yield the gendered equilibrium described in Proposition 3 for the case of non-differential taxation by gender. Equation (66) says that we can focus only on the efficiency aspects of GBT, with the lump sum transfer adjusting to satisfy any distributional consideration. Finally, as we discuss below, the regularity condition is relatively mild and it is likely to hold.

To prove the Proposition, we first consider the right-hand side of equation (67) which gives the relative marginal revenue as a function of the gender difference in marginal tax rates:

$$
\operatorname{MR}(x ; \tau)=\frac{1-\frac{\tau+x}{1-\tau-x}\left(\epsilon_{e_{m}, w_{m}}(x ; \tau)+\epsilon_{n_{m}, w_{m}}(x ; \tau)+\epsilon_{n_{m}, w_{m}}(x ; \tau) \epsilon_{e_{m}, w_{m}}(x ; \tau)\right)}{1-\frac{\tau}{1-\tau}\left(\epsilon_{e_{f}, w_{f}}(\tau)+\epsilon_{n_{f}, w_{f}}(\tau)+\epsilon_{n_{f}, w_{f}}(\tau) \epsilon_{e_{f}, w_{f}}(\tau)\right)}
$$

\footnotetext{
${ }^{32}$ As we show below, $x(\tau)$ is a function, i.e. the solution is unique. After $x(\tau)$ is known, we can plug this equation back to the government's budget constraint and check if the constraint is satisfied. If revenues are lower than $G$, then we increase $\tau$ and the opposite when revenues are higher than $G$. In other words, $\tau$ will depend on the exogenous level of $G$. This procedure defines another fixed point problem which can be shown to converge whenever it starts from the upward sloping part of the Laffer curve. Since utility decreases in the marginal tax rates, the planner will never choose a $\tau$ and a $x(\tau)$ on the "wrong side" of the Laffer curve.

${ }^{33}$ The same comment following Proposition 3 applies. While we focus only on the three extreme cases that isolate the source of the gendered equilibrium, Proposition 4 can be extended to a combination of cases.
} 
First, we note here and prove in Appendix A.7 that the career elasticity, $\epsilon_{e_{m}, w_{m}}$, increases in men's taxes $\tau+x$. Similarly to the case of taxes, we can show that the career elasticity decreases in the effective wage $w_{m} e_{m}$ and increases in the home productivity parameter $\kappa_{m}$, for any $\gamma$. This result verifies the claim in Section 5 that, for equal taxes, men have a less elastic career decision than women whenever gender differences derive from comparative advantage.

Because the wage elasticity of labor supply increases in the ratio of home duties over market hours as shown in equation (42) and because the ratio of home duties over market work is an increasing function of the tax rate as shown in Proposition 1, the labor supply elasticity, $\epsilon_{n_{m}, w_{m}}(x ; \tau)$, in equation (68) increases in $x$. Given that the career elasticity, $\epsilon_{e_{m}, w_{m}}(x ; \tau)$, also increases in men's tax rate, the relative marginal revenue function $M R(x ; \tau)$ is a strictly decreasing function of $x$, for any $\tau>0$. In addition, the relative marginal revenue exceeds unity at the point of non-differential taxation by gender, i.e. $M R(x=0, \tau)>1$, for any $\tau>0$. In other words, at the single tax rate, raising tax revenues from men is easier than raising revenues from women, which is the "Ramsey inverse elasticity rule." This holds because for equal marginal tax rates, men have a less elastic labor supply and career decision than women as discussed in Proposition $3 .^{34}$ The function $M R(x ; \tau)$ is depicted in Figure 1.

Consider the left-hand side of equation (67), which gives the relative marginal cost of taxing men:

$$
M C(x ; \tau)=\frac{z+(1-\gamma)\left(z-\Delta_{m}(x ; \tau)\right) \epsilon_{e_{m}, w_{m}}(x ; \tau)}{z+\gamma\left(z-\Delta_{f}(\tau)\right) \epsilon_{e_{f}, w_{f}}(\tau)}
$$

If there was no career decision or if the career decision was inelastic, then the relative marginal cost would always equal unity. This is because the planner can redistribute wealth across spouses without distortions according to equation (66), which implies that the utility costs of higher marginal tax rates must be equalized across genders. As we discuss below, in that case $x(\tau)>0$ is optimal. An elastic career decision introduces a complication because spouses do not internalize the effects of their career decision on their spouse's utility. This is captured by the last term of the numerator (for the case of men) and the last term of the denominator (for the case of women) in equation (69). Higher tax rates for men distort their decision to pursue higher-wage careers. This, on the one hand, decreases the utility of women because there is sharing inside the family but, on their other hand, this increases women's utility because the relative bargaining power of women increases when men pursue lower-wage careers. As explained in Assumption 1, $z>\Delta_{m}$ implies that the first effect dominates and

\footnotetext{
${ }^{34}$ Looking at equation (68), we see that Assumption 2 is clearly not necessary for our argument. Even when $\epsilon_{e_{f}, w_{f}}>\epsilon_{e_{m}, w_{m}}$, the marginal revenue function is likely to be greater than unity at the point of non-differential taxation because of the gender difference in labor supply elasticities.
} 
that higher tax rates for men introduce a further utility cost for the society.

When the planner contemplates an increase in the marginal tax rate of men relative to women, $x$, the relative marginal cost tends to increase because men's career elasticity, $\epsilon_{e_{m}, w_{m}}(x)$, increases. As a result, women's utility falls faster in the marriage. But on the other hand, the relative marginal cost tends to decrease because the weight on the outside option effect tends to increase $\left(\Delta_{m}(x)\right.$ increases in $\left.x\right)$. Intuitively, singles have a less responsive labor supply than married and as a result the outside option effect receives a larger weight because the off-equilibrium threat of becoming single (and working more) becomes stronger.

In Appendix A.8 we show that $M R^{\prime}(x ; \tau)-M C^{\prime}(x ; \tau)<0$ for any $\tau>0$, i.e. the $M C(x)$ function cuts the $M R(x)$ function from below. This implies that equation (67) has a unique fixed point $x(\tau)$. As a result, we obtain $x(\tau)>0$ if at the point of non-differential taxation by gender, the relative marginal revenue exceeds the relative marginal cost, $M R(x=0 ; \tau)>$ $M C(x=0 ; \tau)$, which is the regularity condition presented above. Figure 1 depicts this situation. This condition is very likely to hold. It always holds when $\gamma$ is sufficiently high. A quick intuition of this result can be obtained by looking at the limiting case $\gamma=1$, i.e. when men make take-it-or-leave-it offers to women, in which case the relative marginal cost function is always smaller than unity, $M C(x ; \tau)<1$. The regularity condition also holds when career is sufficiently inelastic or in a model without a career decision. For the intuition note, as discussed above, that with inelastic careers and optimal redistributive transfers we obtain an equalization of the marginal costs of taxation by gender, $M C(x ; \tau)=1$. When $\gamma$ is relatively low and careers are elastic, $x(\tau)>0$ is optimal under mild additional conditions. ${ }^{35}$

To summarize, when the relative marginal cost of taxing men is smaller than the relative marginal revenue from taxing men at the point of non-differential taxation, $\tau_{m}>\tau_{f}$ is optimal. Since, by the Ramsey inverse elasticity rule, the relative marginal revenue from taxing men exceeds unity at the single tax rate, $\tau_{m}>\tau_{f}$ is optimal whenever society's marginal cost of taxing men is equal to (or smaller than) society's marginal cost of taxing women. This condition is also sufficient for $\tau_{m}>\tau_{f}$ in the case of $\pi_{m}=\pi_{f}=0$ in equation (65).

\subsection{Discussion and Further Implications of GBT}

Under the conditions of Proposition 4, the specific assumption that generates a gendered equilibrium, i.e. whether $\gamma>1 / 2$ or $w_{m}>w_{f}$ or $\kappa_{f}>\kappa_{m}$, does not matter for the result

\footnotetext{
${ }^{35}$ We verify numerically that $x(\tau)>0$ is almost always optimal. One, for instance, condition that generates $x(\tau)>0$ is that $G$ is not trivially low relative to total income in the economy. Another condition is that singles are not too different from married because in this case the increase of $\Delta_{m}$ in equation (69) is dominated by the increase of $\epsilon_{e_{m}, w_{m}}$.
} 
$\tau_{m}>\tau_{f}$. However, the deeper determinant of the gendered equilibrium matters for the redistributive part of taxation, i.e. for equation (66). For instance, when $\gamma>1 / 2$ but the social planner weights men and women equally $(\omega=1 / 2)$, there is a "social dissonance" (Apps and Rees 1988) between society's preferences and the result of the bargaining game in which men have more bargaining power than women. In the case of uneven bargaining power, the planner in general transfers resources lump sum from men to women to ameliorate the social dissonance. A second case arises when $\omega$ is close to $1 / 2$, but women have comparative advantage in home duties. Gender differences in wages $\left(w_{m}>w_{f}\right)$ imply a lump sum transfer from men to women. ${ }^{36}$ Interestingly, the case of $\kappa_{f}>\kappa_{m}$ implies a lump sum transfer from women to men, but as Proposition 4 shows, it also implies higher marginal tax rates on men. Put it differently, in this case the planner transfers resources lump sum to men to offset the absolute advantage of women and then taxes them on a higher marginal tax schedule to minimize distortions because men have lower labor supply elasticities.

GBT changes endogenously the intrafamily bargaining solution. Following the same reasoning that leads to Proposition 3 we conclude that, because of GBT, the allocation of home duties and market opportunities becomes more balanced across genders, women start to pursue higher-wage careers and the elasticities of labor supply start to converge, relative to a system with a single tax rate. Therefore, to the extent that the society values the social goal of promoting women's employment in the market, as so many other gender policies show, GBT offers this additional benefit. However, we have not considered some potential costs. One case arises when $\kappa_{f}>\kappa_{m}$ and there are increasing returns to home production $(\alpha>1)$. If, after GBT is implemented, women work more in the market and men take more home production (for instance, due to a change in the pattern of specialization within the household), there could be welfare losses from the less efficient production of the household good. In principle, the same argument can be raised if one believes that there are increasing returns in the market sector. An additional potential cost of GBT would arise in the case of self-employed, if differential taxation induces couples to shift taxable income from one spouse to the other. In turn, existence of such possibilities for the self-employed, may distort occupational choices.

The idea that GBT endogenously balances the allocation of work across genders may have additional implications in a dynamic extension of the model. If one believes that men and women are biologically identical in their market and home productivity, and with the possible exception of women's comparative advantage in early child development there is no

\footnotetext{
${ }^{36}$ This assumes that the gender difference in the marginal tax rates is not so large to reverse the gap in the social marginal utilities. A similar comment applies to the cases $\gamma>1 / 2$ and $\kappa_{f}>\kappa_{m}$.
} 
reason not to believe so, then gender differences originating within the family will be entirely attributed to cultural or historical factors that favor the man. When the explicit bargaining power of men, $\gamma$, evolves endogenously as a result of a cultural transmission that arises from the internal organization of the family and society's perceptions regarding gender roles, one would expect that the initial implementation of GBT leads to a long-run equilibrium with no gender differences and as a result no need to use GBT.

\section{Concluding Remarks}

In this paper we begin to analyze the effects of Gender-Based Taxation as a potential tax policy. We consider two cases for the organization of the family. In the first case, men and women have different labor supplies because women have a comparative advantage in performing home duties. In the second case, for cultural reasons the intrafamily bargaining process favors the husband. When society can use lump sum transfers to redistribute wealth efficiently across genders, the marginal tax rates are set to minimize labor market distortions. GBT with lower marginal tax rates for women is, under mild conditions, superior to an ungendered tax rate, independently of the deeper reason that sustains a gendered equilibrium which matters only for the redistributive properties of taxation. In what we call the "longrun," spouses react to GBT and as a result the allocation of household duties and labor market opportunities becomes more balanced and the gender gap in labor supplies elasticities becomes smaller.

Rather than reviewing in more detail our results it is worth discussing several important avenues for future research. First, our model does not allow for a realistic marriage market since it considers a society in which marriage is optimal for everybody along the equilibrium path. A proper discussion of the marriage market would require the introduction of some heterogeneity within the pool of men and women and the consideration of a matching or a searching model. An evaluation of these more complicated tax structures would depend undoubtedly on their redistributive properties in a world of heterogeneous households.

Second, we have considered gender-specific tax schedules that apply regardless of marital status. This is a quite different policy from one which taxes differentially only married men and women because, in our case, the government can affect the bargaining positions of spouses through changes in their outside options. Alternatively, if we allowed for different tax rates not only across genders but also within genders by differentiating between singles and married, our model suggests that the government could directly offset the bargaining power of men by 
taxing single men at a higher rate.

Third, our model assumes the structure of the tax instruments as in the Ramsey tradition. Our family model could contribute to the Mirrlees optimum income tax problem, as the elasticity of labor supply and the distribution of wages are key determinants in that model too. The tax policy part of our model would benefit from an analysis closer to that of Mirrlees as the policy of differential taxation by gender redistributes not only within households but also across households.

Fourth, our model does not distinguish between the intensive and extensive margin of the labor supply decision. Note that in a model in which women have a more elastic participation margin, gender-specific transfers conditional on market participation have efficiency benefits similar to the benefits of gender-specific marginal tax rates in our model with an intensive margin of labor supply.

Fifth, we have not allowed for the fact that certain chores (but probably not all, at least for most families) can be purchased in the market. Sixth, for the political economy of GBT it is crucial to allow for lump sum transfers that compensate the losers and model explicitly how singles react to differential taxation by gender. Seventh, a quantitative evaluation of GBT can shed more light on the welfare effects of differential taxation. This exercise would require a richer framework in which we allow for elasticity effects on the extensive margin of labor supply and income effects on women's labor supply.

Finally, a comparison of GBT with other gender and family policies, such as quotas, affirmative action, forced parental leave and public supply of services to families, is necessary within a unified theoretical framework in order to draw policy conclusions. Many types of quantity interventions we observe in practice may be more distortionary and less well targeted at addressing problems which can be addressed by GBT. We see no reason why GBT should not be a favorite "horse" in a race with all these alternative policies, but we still have to run it. 


\section{A Appendix}

\section{A.1 Participation Constraints}

Consider the case of men (the case of women is symmetric). Using the solution presented in Proposition 1 we can write:

$$
\begin{array}{r}
U_{m}-U_{m}^{s}=\gamma\left(z y_{m}+(1+\chi) \frac{\kappa_{m} h_{m}^{\alpha}}{\alpha}-\frac{1}{1+\phi}\left(n_{m}+h_{m}\right)^{1+\phi}-U_{m}^{s}\right)+ \\
+\gamma\left(z y_{f}+(1+\chi) \frac{\kappa_{f} h_{f}^{\alpha}}{\alpha}-\frac{1}{1+\phi}\left(n_{f}+h_{f}\right)^{1+\phi}-U_{f}^{s}\right)
\end{array}
$$

We claim that both parentheses in the right-hand side of equation (A.1) are positive. For the first parenthesis, plugging the solution for $y_{m}$ and $U_{m}^{s}$ presented in Proposition 1, we need to show that:

$$
\begin{array}{r}
z\left(\left(1-\tau_{m}\right) w_{m} n_{m} e_{m}+\pi_{m}\right)+(1+\chi) \frac{\kappa_{m} h_{m}^{\alpha}}{\alpha}-\frac{1}{1+\phi}\left(n_{m}+h_{m}\right)^{1+\phi} \\
>\left(1-\tau_{m}\right) w_{m} n_{m}^{s} e_{m}+\pi_{m}+\frac{\kappa_{m}\left(h_{m}^{s}\right)^{\alpha}}{\alpha}-\frac{1}{1+\phi}\left(n_{m}^{s}+h_{m}^{s}\right)^{1+\phi}
\end{array}
$$

When we insert the singles' solution into the left-hand side of inequality (A.2), we see that the inequality holds strictly for $z>1, \chi>0$ and $c_{i}^{s}=\left(1-\tau_{m}\right) w_{m} n_{m}^{s} e_{m}+\pi_{m}>0$. A similar reasoning shows that the second parenthesis in the right-hand side of equation (A.1) is also positive when evaluated at the singles' solution. It follows that a positive surplus for both spouses is feasible even if the family does not reoptimize. Therefore, after the family optimizes the Nash product, both partners will derive utility that (weakly) exceeds the utility of singles.

\section{A.2 Discussion of Assumption 1}

We verify that there is an area of $z$ 's and $\chi^{\prime}$ 's such that condition (35) in Assumption 1 holds. Using the labor supply functions of singles and married in Proposition 1, we write a relationship between the labor supply of married and the labor supply of singles:

$$
n_{i}=\left(z\left(1-\tau_{i}\right) w_{i} e_{i}\right)^{\frac{1}{\phi}}-\left(\frac{\kappa_{i}(1+\chi)}{z\left(1-\tau_{i}\right) w_{i} e_{i}}\right)^{\frac{1}{1-\alpha}}=z^{\frac{1}{\phi}}\left(n_{i}^{s}+h_{i}^{s}\right)-\left(\frac{1+\chi}{z}\right)^{\frac{1}{1-\alpha}} h_{i}^{s}
$$

Denote by $r_{i}^{s}=h_{i}^{s} / n_{i}^{s}$ the ratio of home duties over market work of singles. Dividing both sides of equation (A.3) by $n_{i}^{s}$ :

$$
\frac{n_{i}}{n_{i}^{s}}=z^{\frac{1}{\phi}}\left(1+r_{i}^{s}\right)-\left(\frac{1+\chi}{z}\right)^{\frac{1}{1-\alpha}} r_{i}^{s}
$$


Inverting both sides of equation (A.4), we rewrite $\Delta_{i}$ (relative labor supply of singles) as:

$$
\Delta_{i}:=\frac{n_{i}^{s}}{n_{i}}=\frac{1}{z^{\frac{1}{\phi}}-\left(\left(\frac{1+\chi}{z}\right)^{\frac{1}{1-\alpha}}-z^{\frac{1}{\phi}}\right) r_{i}^{s}}
$$

The first part of the inequality in Assumption $1\left(1+\chi>z^{1+\frac{1-\alpha}{\phi}}\right)$ guarantees that the parenthesis in the denominator of equation (A.5) is positive, which is a necessary condition for $\Delta_{i}>1$ :

$$
K:=\left(\frac{1+\chi}{z}\right)^{\frac{1}{1-\alpha}}-z^{\frac{1}{\phi}}>0
$$

Using equation (A.5), the assumption $\Delta_{i}>1$ requires:

$$
z^{\frac{1}{\phi}}-K r_{i}^{s}<1 \Longrightarrow r_{i}^{s}(z)>\frac{z^{\frac{1}{\phi}}-1}{K}:=L(z)
$$

Using equation (A.5), the assumption $z>\Delta_{i}$ requires:

$$
z>\frac{1}{z^{\frac{1}{\phi}}-K r_{i}^{s}} \Longrightarrow r_{i}^{s}(z)<\frac{z^{\frac{1}{\phi}}-\frac{1}{z}}{K}:=R(z)
$$

As a result, $z>\Delta_{i}>1$ holds when $L(z)<r_{i}^{s}(z)<R(z)$. For $z=1$ we obtain $r_{i}^{s}(1)>$ $L(1)=R(1)=0$. Using Proposition 1, we see that as $z$ increases, labor supply $n_{i}^{s}$ increases and the amount of home duties $h_{i}^{s}$ falls. Therefore, $r_{i}^{s}(z)=h_{i}^{s} / n_{i}^{s}$ is a decreasing function of $z$. In addition, because $K(z)$ is a decreasing function of $z$, both $R(z)$ and $L(z)$ are increasing functions of $z$. Because $R(z)>L(z)$ for all $z>1, R(z)$ must grow faster than $L(z)$ when $z$ increases. When $K(z)$ approaches zero, which is the case of $(1+\chi)=z^{1+\frac{1-\alpha}{\phi}}$ in Assumption $1, R(z)$ and $L(z)$ approach infinity. Since $r_{i}^{s}(z)$ is positive at $z=1$ and then decreases and since $R(z)$ and $L(z)$ are zero at $z=1$ and then increase without bounds with $R(z)>L(z)$, it follows that there exists an area of $z$ 's such that the condition $z>\Delta_{i}>1$ holds. In addition, because $r_{i}^{s}(z)$ is finite, this area always has the property that $z^{1+\frac{1-\alpha}{\phi}}<(1+\chi)$, consistent with Assumption 1.

\section{A.3 Proof that Marriage Amplifies the Gender Gap in Elasticities}

We need to show that $\epsilon_{n_{f}, w_{f}}-\epsilon_{n_{f}, w_{f}}^{s}>\epsilon_{n_{m}, w_{m}}-\epsilon_{n_{m}, w_{m}}^{s}$. Substituting the formulas for the elasticities of labor supply from equations (42) and (43) we need to show that:

$$
\left(\frac{1}{\phi}+\frac{1}{1-\alpha}\right)\left(\frac{h_{f}}{n_{f}}-\frac{h_{f}^{s}}{n_{f}^{s}}\right)>\left(\frac{1}{\phi}+\frac{1}{1-\alpha}\right)\left(\frac{h_{m}}{n_{m}}-\frac{h_{m}^{s}}{n_{m}^{s}}\right)
$$


Factoring out $n_{i}^{s}$ from both sides of inequality (A.9) and using the fact that $n_{m}^{s}>n_{f}^{s}$, it is sufficient to show that:

$$
h_{f} \Delta_{f}-h_{f}^{s}>h_{m} \Delta_{m}-h_{m}^{s}
$$

or that:

$$
\left(h_{f}-h_{f}^{s}\right)+h_{f}\left(\Delta_{f}-1\right)>\left(h_{m}-h_{m}^{s}\right)+h_{m}\left(\Delta_{m}-1\right)
$$

Since the gender gap in home duties is greater for married couples than for singles (shown in Proposition 3), the first term in the left-hand side of inequality (A.11) is greater than the first term in the right-hand side of inequality (A.11). The second term in the left-hand side of inequality (A.11) is also greater than the second term in the right-hand side of inequality (A.11) because $\Delta_{f}>\Delta_{m}$ and $h_{f}>h_{m}$. This completes the proof.

\section{A.4 Derivation of the Career Elasticity}

To calculate the elasticity (for the case of men), differentiate implicitly the first order condition for optimal careers, equation (30):

$$
\frac{\partial e_{m}}{\partial w_{m}}=\frac{\left(1-\tau_{m}\right)\left[\left(\gamma z n_{m}+(1-\gamma) n_{m}^{s}\right)+w_{m}\left(\gamma z \frac{\partial n_{m}}{\partial w_{m}}+(1-\gamma) \frac{\partial n_{m}^{s}}{\partial w_{m}}\right)\right]}{C^{\prime \prime}-\left(1-\tau_{m}\right) w_{m}\left(\gamma z \frac{\partial n_{m}}{\partial e_{m}}+(1-\gamma) \frac{\partial n_{m}^{s}}{\partial e_{m}}\right)}
$$

We rearrange equation (A.12) to make the wage elasticities of labor supply appear in the above expression:

$$
\frac{\partial e_{m}}{\partial w_{m}}=\frac{\left(1-\tau_{m}\right)\left(\gamma z n_{m}+(1-\gamma) n_{m}^{s}+\gamma z n_{m} \epsilon_{n_{m}, w_{m}}+(1-\gamma) n_{m}^{s} \epsilon_{n_{m}, w_{m}}^{s}\right)}{\frac{C^{\prime}}{e_{m}} E-\left(1-\tau_{m}\right) w_{m}\left(\gamma z \epsilon_{n_{m}, w_{m}} \frac{n_{m}}{e_{m}}+(1-\gamma) \epsilon_{n_{m}, w_{m}}^{s} \frac{n_{m}^{s}}{e_{m}}\right)}
$$

In deriving equation (A.13) we have used the definition of the elasticity of the marginal cost of careers, $E=C^{\prime \prime} e / C^{\prime}{ }^{37}$ The next step is to substitute out from the denominator of equation (A.13) the term $C^{\prime}$ using the first order condition for the optimal career, equation (30), and to collect terms. This leads to:

$$
\frac{\partial e_{m}}{\partial w_{m}}=\frac{\left(1-\tau_{m}\right)\left(\gamma z n_{m}\left(1+\epsilon_{n_{m}, w_{m}}\right)+(1-\gamma) n_{m}^{s}\left(1+\epsilon_{n_{m}, w_{m}}^{s}\right)\right)}{\frac{w_{m}}{e_{m}}\left(1-\tau_{m}\right)\left[E\left(\gamma z n_{m}+(1-\gamma) n_{m}^{s}\right)-\gamma z n_{m} \epsilon_{n_{m}, w_{m}}-(1-\gamma) n_{m}^{s} \epsilon_{n_{m}, w_{m}}^{s}\right]}
$$

Finally, factoring out $n_{m}$ from the numerator and the denominator, using the definition of $\Delta_{m}:=n_{m}^{s} / n_{m}$ and simplifying, we obtain:

$$
\frac{\partial e_{m}}{\partial w_{m}}=\frac{e_{m}}{w_{m}} \frac{\gamma z\left(1+\epsilon_{n_{m}, w_{m}}\right)+(1-\gamma) \Delta_{m}\left(1+\epsilon_{n_{m}, w_{m}}^{s}\right)}{\gamma z\left(E-\epsilon_{n_{m}, w_{m}}\right)+(1-\gamma) \Delta_{m}\left(E-\epsilon_{n_{m}, w_{m}}^{s}\right)}
$$

Multiplying both sides of equation (A.15) by $w_{m} / e_{m}$ leads to equation (44). A similar derivation leads to equation (45) for women.

\footnotetext{
${ }^{37}$ Note that we have also used $\epsilon_{n_{m}, w_{m}}=\epsilon_{n_{m}, e_{m}}$.
} 


\section{A.5 Excluding $\pi_{m}>0$ and $\pi_{f}>0$}

Using the results of Section 6.1, we can write the first order conditions (50) and (51) respectively as:

$$
\begin{gathered}
\lambda=(\gamma z+(1-\gamma)) \omega V_{m}^{\prime}+(1-\gamma)(z-1)(1-\omega) V_{f}^{\prime} \\
\lambda=\gamma(z-1) \omega V_{m}^{\prime}+(z(1-\gamma)+\gamma)(1-\omega) V_{f}^{\prime}
\end{gathered}
$$

Combining equations (A.16) and (A.17) we obtain:

$$
\frac{\lambda}{z}=(1-\omega) V_{f}^{\prime}=\omega V_{m}^{\prime}
$$

We show that lump sum transfers cannot be positive for both spouses. Using the results of Section 6.1 and equation (A.18), we write the first order condition for the optimal $\tau_{m}$, equation (48), and the first order condition for the optimal $\tau_{f}$, equation (49), as:

$$
\begin{array}{r}
-(1-\gamma)\left(z-\Delta_{m}\right) \frac{1-\tau_{m}}{\tau_{m}} \epsilon_{e_{m}, \tau_{m}} \geq z\left(\epsilon_{e_{m}, \tau_{m}}+\epsilon_{n_{m}, \tau_{m}}+\epsilon_{n_{m}, w_{m}} \epsilon_{e_{m}, \tau_{m}}\right) \\
-\gamma\left(z-\Delta_{f}\right) \frac{1-\tau_{f}}{\tau_{f}} \epsilon_{e_{f}, \tau_{f}} \geq z\left(\epsilon_{e_{f}, \tau_{f}}+\epsilon_{n_{f}, \tau_{f}}+\epsilon_{n_{f}, w_{f}} \epsilon_{e_{f}, \tau_{f}}\right)
\end{array}
$$

Since all tax elasticities are negative and all wage elasticities are positive, equations (A.19) and (A.20) hold with strict inequality, i.e. $\tau_{m}=\tau_{f}=0$ (this also holds when careers are inelastic). But when marginal tax rates are set equal to zero, it is impossible to finance $G>0$ and the transfers. Therefore, this case is excluded.

\section{A.6 Proof that when $\pi_{m}>0$ and $\pi_{f}=0$ then $\tau_{m}=0$ and $\tau_{f}>0$}

When $\pi_{m}>0$, the first order conditions (50) and (51) become respectively:

$$
\begin{gathered}
\lambda>\gamma(z-1) \omega V_{m}^{\prime}+(z(1-\gamma)+\gamma)(1-\omega) V_{f}^{\prime} \\
\lambda=(\gamma z+(1-\gamma))(1-\omega) V_{m}^{\prime}+(1-\gamma)(z-1)(1-\omega) V_{f}^{\prime}
\end{gathered}
$$

Combining equations (A.21) and (A.22) we obtain:

$$
\omega V_{m}^{\prime}>\lambda=(\gamma z+(1-\gamma)) \omega V_{m}^{\prime}+(1-\gamma)(z-1)(1-\omega) V_{f}^{\prime}>(1-\omega) V_{f}^{\prime}
$$

Under equation (A.23), the first order condition for $\tau_{m}$, equation (48), becomes equation (A.19). Since all tax elasticities are negative and all wage elasticities are positive, we obtain $\tau_{m}=0$. Since $G+\pi_{m}>0$, it follows that the planner sets $\tau_{f}>0$. 


\section{A.7 Proof that the Career Elasticity Increases in the Marginal Tax Rate}

Using the definition of the career elasticity in equation (44) and after some algebra we obtain:

$$
\begin{array}{r}
\frac{\partial \epsilon_{e_{m}, w_{m}}}{\partial(\tau+x)} \propto-\left(\epsilon_{n_{m}, w_{m}}-\epsilon_{n_{m}, w_{m}}^{s}\right)^{2} \frac{\gamma(1-\gamma) z n_{m} n_{m}^{s}}{1-\tau-x}+ \\
\left(\gamma z n_{m}+(1-\gamma) n_{m}^{s}\right)\left(\gamma z n_{m} \epsilon_{n_{m}, w_{m}}^{\prime}(1-\gamma) n_{m}^{s}\left(\epsilon_{n_{m}, w_{m}}^{s}\right)^{\prime}\right)
\end{array}
$$

where $\epsilon_{n_{m}, w_{m}}^{\prime}$ denotes the derivative of married men's wage elasticity of labor supply with respect to the tax rate $\tau+x$ and $\left(\epsilon_{n_{m}, w_{m}}^{s}\right)^{\prime}$ is the derivative of single men's wage elasticity of labor supply with respect to the tax rate.

Rearranging equation (A.24), the career elasticity increases in the marginal tax rate when:

$$
\begin{array}{r}
\frac{(1-\tau-x) \gamma z n_{m}}{(1-\gamma) n_{m}^{s}} \epsilon_{n_{m}, w_{m}}^{\prime}+\frac{(1-\tau-x)(1-\gamma) n_{m}^{s}}{\gamma n_{m} z}\left(\epsilon_{n_{m}, w_{m}}^{s}\right)^{\prime}> \\
\left(\epsilon_{n_{m}, w_{m}}-\epsilon_{n_{m}, w_{m}}^{s}\right)^{2}-(1-\tau-x)\left(\epsilon_{n_{m}, w_{m}}^{\prime}-\left(\epsilon_{n_{m}, w_{m}}^{s}\right)^{\prime}\right)
\end{array}
$$

We claim that inequality (A.25) holds true. To see this, first note that because the wage elasticity of labor supply increases in the ratio of home duties over market hours and because this ratio is increasing in the tax rate, we obtain $\epsilon_{n_{m}, w_{m}}^{\prime}>0$ and $\left(\epsilon_{n_{m}, w_{m}}^{s}\right)^{\prime}>0$. Therefore, the left-hand side of inequality (A.25) is positive. Second, we note that the right-hand side of the inequality is negative. To verify this one needs to simply use the formulas:

$$
\epsilon_{n_{m}, w_{m}}=\frac{1}{\phi}+\left(\frac{1}{\phi}+\frac{1}{1-\alpha}\right) \frac{h_{m}}{n_{m}}
$$

and

$$
(1-\tau-x) \epsilon_{n_{m}, w_{m}}^{\prime}=\frac{h_{m}}{n_{m}}\left(\frac{1}{\phi}+\frac{1}{1-\alpha}\right)\left(\frac{1}{\phi}+\frac{1}{1-\alpha}+\left(\frac{1}{\phi}+\frac{1}{1-\alpha}\right) \frac{h_{m}}{n_{m}}\right)
$$

and the corresponding formulas for $\epsilon_{n_{m}, w_{m}}^{s}$ and $\left(\epsilon_{n_{m}, w_{m}}^{s}\right)^{\prime}$ on the right-hand side of inequality (A.25).

\section{A.8 Proof that $M C(x)$ Cuts $M R(x)$ from Below}

Define the function:

$$
J(x ; \tau)=M R(x ; \tau)-M C(x ; \tau)
$$

where $M R(x ; \tau)$ is given by equation (68) and $M C(x ; \tau)$ is given by equation (69). We will show that the function $J(x ; \tau)$ is decreasing in $x$ for any $\tau \geq 0$. We define the terms:

$$
H(\tau)=z+\gamma\left(z-\Delta_{f}(\tau)\right) \epsilon_{e_{f}, w_{f}}(\tau)
$$




$$
L(\tau)=1-\frac{\tau}{1-\tau}\left(\epsilon_{e_{f}, w_{f}}(\tau)+\epsilon_{n_{f}, w_{f}}(\tau)+\epsilon_{e_{f}, w_{f}}(\tau) \epsilon_{n_{f}, w_{f}}(\tau)\right)
$$

Note that these terms depend only on $\tau$ and not on $x$. From Assumption $1\left(z>\Delta_{f}\right)$ we note that $H(\tau)>z$. We also have $0<L(\tau) \leq 1$ because all elasticities are positive $(L(\tau) \leq 1)$ and when $\tau$ is chosen optimally, the government never choses tax rates that lie on the "wrong side" of the Laffer curve $(L(\tau)>0)$.

Using the definitions (A.27) and (A.28) on equations (68) and (69) and since $H(\tau)$ and $L(\tau)$ do not depend on $x$, we obtain the result that $J$ is decreasing in $x$ if and only if the function $\tilde{J}$ is decreasing in $x$ :

$$
\begin{array}{r}
\tilde{J}(x ; \tau)=-\left(z+(1-\gamma)\left(z-\Delta_{m}(x ; \tau)\right) \epsilon_{e_{m}, w_{m}}(x ; \tau)\right) L(\tau)+ \\
+\left[1-\frac{\tau+x}{1-\tau-x}\left(\epsilon_{e_{m}, w_{m}}(x ; \tau)+\epsilon_{n_{m}, w_{m}}(x ; \tau)+\epsilon_{e_{m}, w_{m}}(x ; \tau) \epsilon_{n_{m}, w_{m}}(x ; \tau)\right)\right] H(\tau)
\end{array}
$$

Denoting with primes the derivatives of functions with respect to $x$, we obtain:

$$
\begin{array}{r}
\tilde{J}^{\prime}(x ; \tau)=-(1-\gamma)\left(z-\Delta_{m}\right) \epsilon_{e_{m}, w_{m}}^{\prime} L(\tau)+(1-\gamma) \epsilon_{e_{m}, w_{m}} L(\tau) \Delta_{m}^{\prime}- \\
-\frac{H(\tau)}{(1-\tau-x)^{2}}\left(\epsilon_{e_{m}, w_{m}}+\epsilon_{n_{m}, w_{m}}+\epsilon_{e_{m}, w_{m}} \epsilon_{n_{m}, w_{m}}\right)- \\
-\frac{(\tau+x) H(\tau)}{(1-\tau-x)}\left(\epsilon_{e_{m}, w_{m}}^{\prime}+\epsilon_{n_{m}, w_{m}}^{\prime}+\epsilon_{e_{m}, w_{m}}^{\prime} \epsilon_{n_{m}, w_{m}}+\epsilon_{e_{m}, w_{m}} \epsilon_{n_{m}, w_{m}}^{\prime}\right)
\end{array}
$$

In the text and previously in the Appendix we showed that all elasticities are increasing in the marginal tax rate. Therefore, in equation (A.30) the first, third and fourth terms are negative. The second term is positive, since $\Delta_{m}$ increases in the marginal tax rate. To see this, note that equation (A.5) in the Appendix shows that $\Delta_{i}$ increases in the ratio of home duties to market work for singles and Proposition 1 shows that this ratio increases in the marginal tax rate.

To show that $\tilde{J}^{\prime}(x ; \tau)<0$ it is sufficient to show that the negative term $-H(\tau) \epsilon_{e_{m}, w_{m}}(1+$ $\left.\epsilon_{n_{m}, w_{m}}\right) /(1-\tau-x)^{2}$ (part of the third term in equation (A.30)) dominates the positive term $(1-\gamma) \epsilon_{e_{m}, w_{m}} L(\tau) \Delta_{m}^{\prime}$ in equation (A.30). Our strategy is to establish an upper bound for the positive term $(1-\gamma) \epsilon_{e_{m}, w_{m}} L(\tau) \Delta_{m}^{\prime}$ and show that this upper bound is smaller in absolute value than the term $-H(\tau) \epsilon_{e_{m}, w_{m}}\left(1+\epsilon_{n_{m}, w_{m}}\right) /(1-\tau-x)^{2}$.

Consider the expression $Q=(1-\tau-x) n_{m}(x ; \tau)\left(\gamma z+(1-\gamma) \Delta_{m}(x ; \tau)\right)$. $Q$ is decreasing in $x$ because it equals $(1-\tau-x)\left(\gamma z n_{m}(x ; \tau)+(1-\gamma) n_{m}^{s}(x ; \tau)\right)$ and from Proposition 1 , labor supply decreases in taxes. Therefore, denoting with primes the derivatives of functions with respect to $x$, we have:

$$
Q^{\prime}=-\left(\gamma z n_{m}+(1-\gamma) n_{m}^{s}\right)+(1-\tau-x)\left(\gamma z+(1-\gamma) \Delta_{m}\right) n_{m}^{\prime}+(1-\tau-x) n_{m}(1-\gamma) \Delta_{m}^{\prime}<0
$$


Multiplying equation (A.31) by $n_{m}$, using the definitions $\Delta_{m}:=n_{m}^{s} / n_{m}$ and $\epsilon_{n_{m}, w_{m}}:=$ $-(1-\tau-x) n_{m}^{\prime} / n_{m}$ and rearranging we obtain:

$$
Q^{\prime}=-\left(\gamma z+(1-\gamma) \Delta_{m}\right)\left(1+\epsilon_{n_{m}, w_{m}}\right)+(1-\tau-x)(1-\gamma) \Delta_{m}^{\prime}<0
$$

Therefore:

$$
\Delta_{m}^{\prime}<\frac{\left(\gamma z+(1-\gamma) \Delta_{m}\right)\left(1+\epsilon_{n_{m}, w_{m}}\right)}{(1-\gamma)(1-\tau-x)}
$$

Since from Assumption 1 we have $z>\Delta_{m}$, we obtain $\gamma z+(1-\gamma) \Delta_{m}<z$. Therefore, inequality (A.33) is written as:

$$
\Delta_{m}^{\prime}<\frac{z\left(1+\epsilon_{n_{m}, w_{m}}\right)}{(1-\gamma)(1-\tau-x)}
$$

Using inequality (A.34), we can establish an upper bound for the positive term (1 $\gamma) \epsilon_{e_{m}, w_{m}} L(\tau) \Delta_{m}^{\prime}$ :

$$
(1-\gamma) \epsilon_{e_{m}, w_{m}} L(\tau) \Delta_{m}^{\prime}<L(\tau) \frac{z \epsilon_{e_{m}, w_{m}}\left(1+\epsilon_{n_{m}, w_{m}}\right)}{1-\tau-x}
$$

Finally, we take:

$$
(1-\gamma) \epsilon_{e_{m}, w_{m}} L(\tau) \Delta_{m}^{\prime}<L(\tau) \frac{z \epsilon_{e_{m}, w_{m}}\left(1+\epsilon_{n_{m}, w_{m}}\right)}{1-\tau-x}<H(\tau) \frac{\epsilon_{e_{m}, w_{m}}\left(1+\epsilon_{n_{m}, w_{m}}\right)}{(1-\tau-x)^{2}}
$$

Inequality (A.36) states that the absolute value of the (negative) term $-H(\tau) \epsilon_{e_{m}, w_{m}}(1+$ $\left.\epsilon_{n_{m}, w_{m}}\right) /(1-\tau-x)^{2}$ is greater than the upper bound of the (positive) term $(1-\gamma) \epsilon_{e_{m}, w_{m}} L(\tau) \Delta_{m}^{\prime}$ given in inequality (A.35). This holds because $1-\tau-x \leq 1$ and, as previously established, $H(\tau)>z>1$ and $L(\tau) \leq 1$. 


\section{References}

Aguiar, Mark, and Erik Hurst. 2007. "Measuring Trends in Leisure: The Allocation of Time over Five Decades." Quarterly Journal of Economics, 122(3): 969-1006.

Akerlof, George. 1978. "The Economics of "Tagging" as Applied to the Optimal Income Tax, Welfare Programs, and Manpower Planning." American Economic Review, 68(1): 8-19.

Albanesi, Stefania, and Claudia Olivetti. 2007. "Gender Roles and Technological Progress." NBER Working Paper No. 13179.

Albanesi, Stefania, and Claudia Olivetti. 2009. "Home Production, Market Production and the Gender Wage Gap: Incentives and Expectations." Review of Economic Dynamics, 12(1): 80-107.

Alesina, Alberto, and Paola Giuliano. 2010. "The Power of the Family." Journal of Economic Growth, 15(2): 93-125.

Apps, Patricia, and Ray Rees. 1988. "Taxation and the Household." Journal of Public Economics, 35(3): 355-369.

Apps, Patricia, and Ray Rees. 1999a. "On the Taxation of Trade Within and Between Households." Journal of Public Economics, 73(2): 241-263.

Apps, Patricia, and Ray Rees. 1999b. "Joint vs. Individual Taxation in Models of Household Production." Journal of Political Economy, 107(2): 393-403.

Apps, Patricia, and Ray Rees. 2007. "The Taxation of Couples." IZA Discussion Paper No. 2910.

Atkinson, Anthony B., and Joseph E. Stiglitz. 1972. "The Structure of Indirect Taxation and Economic Efficiency." Journal of Public Economics, 1(1): 97-119.

Becker, Gary S. 1974. "A Theory of Marriage: Part II." Journal of Political Economy, 82(2): S11-S26.

Becker, Gary S. 1985. "Human Capital, Effort and the Sexual Division of Labor." Journal of Labor Economics, 3(1): 33-58.

Blau, Francine D., and Lawrence M. Kahn. 2007. "Changes in the Labor Supply Behavior of Married Women: 1980-2000." Journal of Labor Economics, 25(3): 393-438.

Blundell, Richard, and Thomas MaCurdy. 1999. "Labor supply: A review of alternative approaches." In Orley Ashenfelter and David Card (eds.) Handbook of Labor Economics, vol. 3A, Amsterdam: Elsevier.

Boskin, Michael, and Eytan Sheshinski. 1983. "Optimal Tax Treatment of the Family: Married Couples." Journal of Public Economics, 20(3): 281-297. 
Bosworth, Barry, and Gary Burtless. 1992. "Effects of Tax Reform on Labor Supply, Investment, and Savings." Journal of Economic Perspectives, 6(1): 3-25.

Brett, Craig. 1998. "Tax Reform and Collective Family Decision-Making." Journal of Public Economics, 70(3): 425-440.

Browning, Martin, Francois Bourguignon, Pierre-André Chiappori, and Valerie Lechene. 1994. "Incomes and Outcomes: A Structural Model of Intrahousehold Allocation." Journal of Political Economy, 102(6): 1067-1096.

Browning, Martin, and Pierre-André Chiappori. 1998. "Efficient Intrahousehold Allocations: A General Characterization and Empirical Tests." Econometrica, 66(6): $1241-1278$.

Browning, Martin, Pierre-André Chiappori, and Arthur Lewbel. 2006. "Estimating Consumption Economies of Scale, Adult Equivalence Scales, and Household Bargaining Power." University of Oxford Discussion Paper No. 289.

Burda, Michael, Dan Hamermesh, and Philippe Weil. 2007. "Total Work, Gender and Social Norms." NBER Working Paper No. 13000.

Chiappori, Pierre-André. 1988. "Rational Household Labor Supply." Econometrica, 56(1): 63-89.

Chiappori, Pierre-André. 1992, "Collective Labor Supply and Welfare." Journal of Political Economy, 100(3): 437-467.

Cremer Helmuth, Firouz Gahvari, and Jean-Marie Lozachmeur. 2010. "Tagging and Income Taxation: Theory and an Application." American Economic Journal: Economic Policy, 2(1): 31-50.

Diamond, Peter A. 1998. "Optimal Income Taxation: An Example with a U-Shaped Pattern of Optimal Marginal Tax Rates." American Economic Review, 88(1): 83-95.

Diamond, Peter A., and James A. Mirrlees. 1971a. "Optimal Taxation and Public Production, I: Production Efficiency." American Economic Review, 61(1): 8-27.

Diamond, Peter A., and James A. Mirrlees. 1971b. "Optimal Taxation and Public Production, II: Tax Rules." American Economic Review, 61(3): 261-278.

Feldstein, Martin, and Jeffrey B. Liebman. 2002. "Social Security." In Allan J. Auerbach and Martin Feldstein (eds.) Handbook of Public Economics, Vol 4, Elsevier.

Fernandez, Raquel. 2007. "Culture as Learning: The Evolution of Female Labor Force Participation over a Century." NBER Working Paper No. 13373.

Friedberg, Leora, and Anthony Webb. 2006. "Determinants and Consequences of Bargaining Power in Households." NBER Working Paper No. 12367. 
Gelber, Alexander M. 2010. "Taxation and Family Labor Supply." Harvard University, mimeo.

Goldin, Claudia. 2006. "The Quiet Revolution that Transformed Women's Employment Education and Family." American Economic Review Papers and Proceedings, 96(2): $1-23$.

Goldin, Claudia, Lawrence F. Katz, and Ilyana Kuziemko. 2006. "The Homecoming of American College Women: The Reversal of the College Gender Gap." Journal of Economic Perspectives, 20(4): 133-156.

Gottfried, Peter, and Wolfram F. Richter. 1999. "The Tax Unit and Household Production: Comment." Journal of Political Economy, 107(2): 404-409.

Greenwood, Jeremy, Ananth Seshadri, and Mehmet Yorukoglu. 2005. "Engines of Liberation." Review of Economic Studies, 72(1): 109-133.

Gugl, Elisabeth. 2009. "Income Splitting, Specialization, and Intra-Family Distribution." Canadian Journal of Economics, 42(3): 1050-1071.

Guner, Nezih, Remzi Kaygusuz, and Gustavo Ventura. 2010. "Taxation and Household Labor Supply." UAB, mimeo.

Ichino, Andrea, and Enrico Moretti. 2009. "Biological Gender Differences, Absenteeism and the Earning Gap." American Economic Journal: Applied Economics, 1(1): 183-218.

Jaumotte, Florence. 2003. "Female Labour Force Participation: Past Trends and Main Determinants in OECD countries." OECD Paris Economics Department Working Papers 376.

Kaplow, Louis. 2008. The Theory of Taxation and Public Economics. Princeton University Press.

Kleven Henrik J., Claus T. Kreiner, and Emmanuel Saez. 2009. "The Optimal Income Taxation of Couples." Econometrica, 77(2): 537-560.

Kremer, Michael. 2003. "Should Taxes be Independent of Age?" Harvard University, mimeo.

Lundberg, Shelly, and Robert A. Pollak. 1993. "Separate Spheres Bargaining and the Marriage Market." Journal of Political Economy, 101(6): 988-1010.

Lundberg, Shelly, and Robert A. Pollak. 1996. "Bargaining and Distribution in Marriage." Journal of Economic Perspectives, 10(4): 139-158.

Lundberg, Shelly, Robert A. Pollak, and Terence Wales. 1997. "Do Husbands and Wives Pool their Resources? Evidence from the U.K. Child Tax Credit." Journal of Human Resources, 32(3): 463-80. 
Mankiw, N. Gregory, and Matthew Weinzierl. 2010. "The Optimal Taxation of Height: A Case Study of Utilitarian Income Redistribution." American Economic Journal: Economic Policy, 2(1): 155-176.

Manser, Marilyn, and Murray Brown. 1980. "Marriage and Household Decision Making: A Bargaining Analysis." International Economic Review, 21(1): 31-44.

McElroy, Marjorie B., and Mary Horney. 1981. "Nash-Bargained Household Decisions: Towards a Generalization of the Theory of Demand." International Economic Review, 22(2): 333-349.

Mirrlees, James A. 1971. "An Exploration in the Theory of Optimum Income Taxation." Review of Economic Studies, 38(114): 175-208.

Nelson, Julie A. 1988. "Household Economies of Scale in Consumption: Theory and Evidence." Econometrica, 56(6): 1301-1314.

Piggott, John, and John Whalley. 1996. "The Tax Unit and Household Production." Journal of Political Economy, 104(2): 398-418.

Pollak, Robert A. 2007. "Family Bargaining and Taxes: A Prolegomenon to the Analysis of Joint Taxation." IZA Working Paper No. 3109.

Ramsey, Frank P. 1927. "A Contribution to the Theory of Taxation." Economic Journal, 37(145): 47-61.

Rosen, Harvey S. 1977. "Is It Time to Abandon Joint Filing?" National Tax Journal, 30(4): 423-428.

Samuelson, Paul. 1956. "Social Indifference Curves." Quarterly Journal of Economics, 70(1): 1-22.

Thomas, Duncan. 1990. "Intra-Household Resource Allocation: An Inferential Approach." Journal of Human Resources, 25(4): 635-664.

Vermeulen, Frederic. 2002. "Collective Household Models: Principles and Main Results." Journal of Economic Surveys, 16(4): 533-564.

Weinzierl, Matthew. 2008. "The Surprising Power of Age-Dependent Taxes." Harvard University, mimeo.

Zafar, Basit. 2009. "College Major Choice and the Gender Gap." Federal Reserve Bank of New York Staff Report No. 364. 
Table 1: OECD (2003): Marginal Tax Rates in 2001

\begin{tabular}{cccccccc}
\hline Country & Second Earner & Single & Ratio & Second Earner & Single & Ratio & Type of Taxation (1999) \\
\hline \hline Canada & 32 & 21 & 1.5 & 36 & 27 & 1.4 & Separate \\
France & 26 & 21 & 1.2 & 26 & 27 & 1.0 & Joint \\
Germany & 50 & 34 & 1.5 & 53 & 42 & 1.3 & Joint \\
Italy & 38 & 24 & 1.6 & 39 & 29 & 1.4 & Separate \\
Japan & 18 & 15 & 1.2 & 18 & 16 & 1.1 & Separate \\
Spain & 21 & 13 & 1.6 & 23 & 18 & 1.3 & Separate/Joint \\
Sweden & 30 & 30 & 1.0 & 28 & 33 & 0.9 & Separate \\
UK & 24 & 19 & 1.3 & 26 & 24 & 1.1 & Separate \\
US & 29 & 22 & 1.3 & 30 & 26 & 1.2 & Joint/Optional \\
Average & 28 & 21 & 1.4 & 31 & 25 & 1.2 & \\
\hline \hline
\end{tabular}

Notes: The relevant "marginal" tax rate for women's decision to participate in the labor market is the average tax rate on second earners. The husband is assumed to earn 100\% of Average Productive Worker (APW). The family is assumed to have 2 children. In Columns (2)-(4), women are assumed to earn $67 \%$ of APW. In Columns (5)-(7), women are assumed to earn $100 \%$ of APW. Source: Jaumotte (2003). 
Figure 1: Gender-Based Taxation

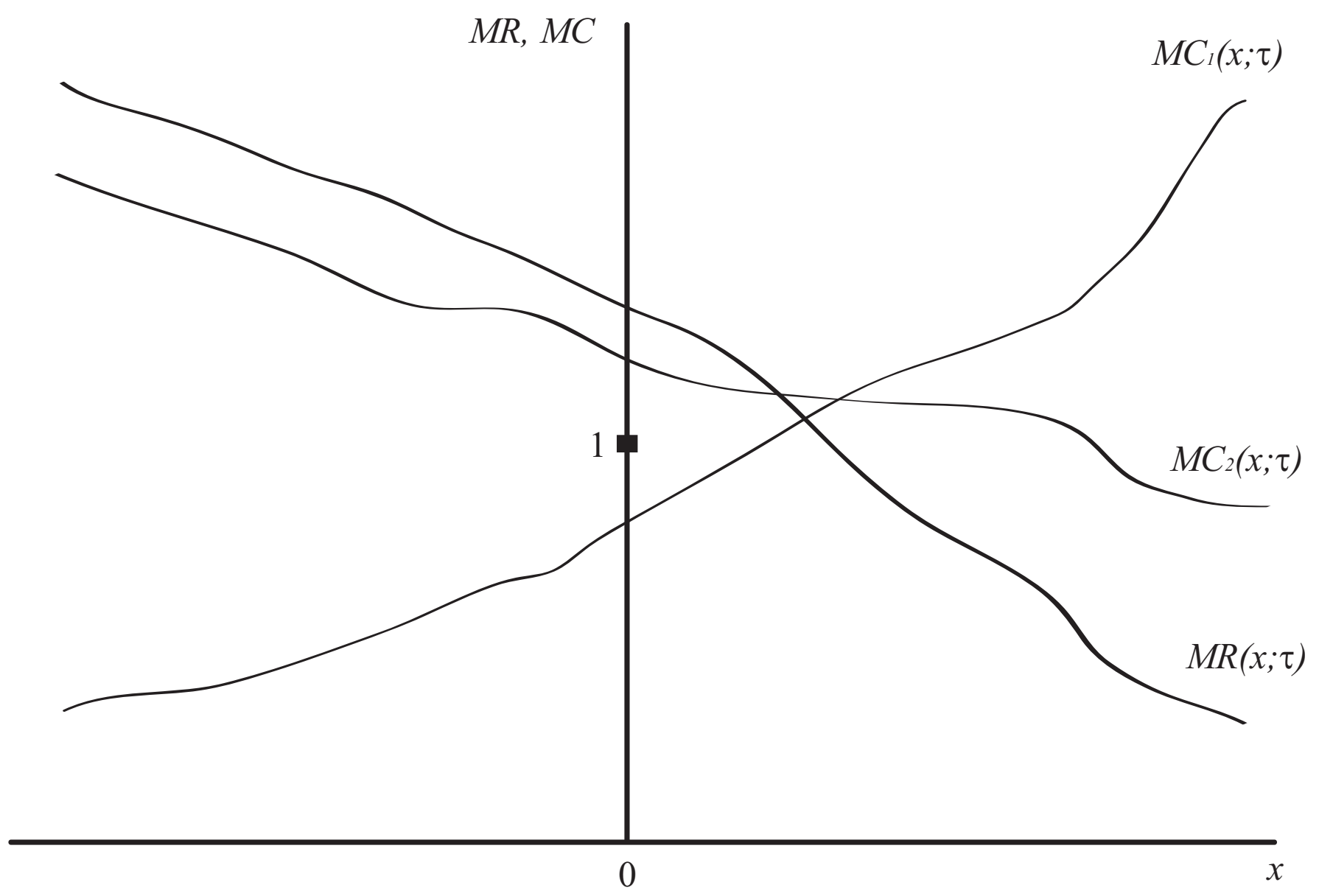

Notes: The vertical axis depicts the relative marginal revenue function $(M R)$ given by equation (68) and the relative marginal cost function $(M C)$ given by equation (69). The horizontal axis depicts the gender difference in marginal tax rates $x(\tau)=\tau_{m}-\tau_{f}$ for a given level of $\tau_{f}=\tau$. As the Figure shows, the relative marginal revenue function is decreasing and exceeds unity at the point of non-differential taxation $(x(\tau)=0)$. The relative marginal cost function can be increasing or decreasing. The relative marginal cost function intersects the relative marginal revenue function at most once and from below. The Figure depicts that the fixed point is positive, $x(\tau)>0$, when the relative marginal cost is smaller than the relative marginal revenue at the point of non-differential taxation by gender $(x(\tau)=0)$. 